\title{
0 surto da COVID-19 e as respostas da administração municipal: munificência de recursos, vulnerabilidade social e eficácia de ações públicas
}

\author{
Nobuiuki Costa Ito ${ }^{1}$ \\ Leandro Simões Pongeluppe ${ }^{2}$ \\ 1 Ibmec São Paulo, São Paulo / SP - Brasil \\ 2 University of Toronto - Rotman School of Management, Toronto / ON - Canadá
}

Diante de uma situação sem precedentes do surto da doença do coronavírus 2019 (COVID-19), os agentes públicos no nível do município não têm referências claras ou políticas testadas. Nessa situação, a tomada de decisão pode se tornar um processo controverso. Este artigo fornece subsídios para gestores municipais lidarem com os estágios iniciais do surto de COVID-19. Analisamos as ações das prefeituras de todos os 52 municípios brasileiros com pelo menos trinta dias desde o primeiro caso confirmado da COVID-19. Utilizamos a fuzzy-set Comparative Qualitative (fsQCA) para identificar as combinações de fatores contextuais e ações públicas que reduziram a transmissão da COVID-19 durante o estágio inicial crítico. Os resultados empíricos mostram três caminhos principais para orientar a formulação de políticas: (1) um caminho de colaboração plural que envolve os setores público e privado na presença de um sistema de saúde frágil; (2) um caminho de ação pública que forneça programas de ajuda através de intensa colaboração dentro da burocracia pública; e (3) um caminho baseado nos recursos de um sistema de saúde bem estruturado.

Palavras-chave: COVID-19; municípios; ação pública.

\section{El brote de COVID-19 y las respuestas de la administración municipal: munificencia de recursos, vulnerabilidad social y efectividad de las acciones públicas}

Ante una situación sin precedentes de brote de la enfermedad por coronavirus 2019 (COVID-19), los funcionarios públicos a nivel municipal no tienen puntos de referencia claros ni políticas probadas. En esta situación, la toma de decisiones se convierte en un proceso controvertido. Este documento proporciona información para que los agentes municipales brasileños puedan hacer frente a las etapas iniciales del brote de COVID-19. Analizamos las acciones tomadas por los ayuntamientos de los 52 municipios brasileños que llevaban al menos treinta días desde el primer caso confirmado de COVID-19. Utilizamos un análisis cualitativo comparativo de conjunto difuso (fsQCA) para identificar las combinaciones de factores contextuales y acciones públicas que redujeron la transmisión de la COVID-19 durante la etapa inicial crítica. Los resultados empíricos muestran tres caminos principales para guiar la formulación de políticas: (1) un camino de colaboración plural que involucre a los sectores público y privado en presencia de un sistema de salud frágil; (2) una vía de acción pública que proporcione programas de ayuda a través de una intensa colaboración dentro de la burocracia pública; y (3) una ruta basada en los recursos de un sistema de salud bien estructurado.

Palabras clave: COVID-19; municipios; acción pública. 


\section{The COVID-19 outbreak and the municipal administration responses: resource munificence, social vulnerability, and the effectiveness of public actions}

Facing the unprecedented situation of the COVID-19 pandemic, public officials at the municipality-level have no clear benchmarks or tested policies. In this situation, decision-making becomes a controversial process. This article provides insights for public agents in the Brazilian municipalities to deal with the initial stages of the COVID-19 pandemic. We analyzed the actions taken by city halls of the 52 Brazilian municipalities at least thirty days since the first confirmed case of COVID-19. We used a fuzzy-set Qualitative Comparative Analysis (fsQCA) to identify the combinations of contextual factors and public actions that reduced COVID-19 transmission during the critical initial stage. The empirical results show three main paths to guide policy-making: (1) a plural collaboration path involving public and private sectors, operating in a fragile health system; (2) a public action path providing aid programs through intense collaboration inside public bureaucracy; and (3) a resource-based path relying on a well-structured health system.

Keywords: COVID-19; municipality; public action.

\section{INTRODUÇ̃̃O}

Qual é a melhor resposta de um governo local nos estágios iniciais de uma pandemia? A pandemia da doença do coronavírus 2019 (doravante COVID-19) é uma situação sem precedentes nos tempos modernos. A séria ameaça para a saúde pública promove o debate sobre ações tomadas por governantes. Entretanto, sem políticas testadas e consolidadas, a tomada de decisão transforma-se em um processo controverso. Neste contexto, informações ou ações específicas podem ser considerada tanto exageradas quanto insuficientes, dependendo da perspectiva do analista (Melo \& Cabral, no prelo). Apesar do número significativo de estudos sobre os aspectos epidemiológicos da COVID-19, a evidência sobre a eficácia das ações dos governos é ainda escassa.

Até o dia 16 de abril de 2020, no início do processo de coleta de dados desse estudo, o Brasil tinha quase 29.000 casos da COVID-19 e mais de 1.700 óbitos reportados. O primeiro caso apareceu na cidade de São Paulo em 25 de fevereiro. Desde então, 1.152 municípios estão lidando com ao menos um caso confirmado da COVID-19. Levou-se 52 dias para o coronavírus alcançar mais de $20 \%$ dos municípios de um país de tamanho continental. O Brasil é grande e heterogêneo e, assim, os governos municipais enfrentam o surto da COVID-19 em contextos bem distintos e possuindo diferentes conjuntos de recursos e capacidades. Esse artigo é uma tentativa de identificar quais as ações públicas, no nível municipal, tiveram sucesso em reduzir a transmissão da COVID-19.

Para isso, foram coletado dados dos 52 municípios brasileiros onde, no dia 16 de abril, havia ao menos 30 dias desde o primeiro caso confirmado da COVID-19. O foco no período dos 30 dias iniciais deve-se ao entendimento de que as ações implementadas durante a fase inicial têm impacto mais duradouro, dado o crescimento exponencial da transmissão da doença. No processo de coleta de dados, desenvolveu-se medidas para capturar duas condições amplas em cada município, a saber: (i) características contextuais do município; e (ii) as estruturas de governança e ações tomadas pelas prefeituras para combater a doença. Como pode-se imaginar, não há fórmula mágica para ter sucesso no combate à doença. Portanto, seria ingênuo buscar por uma solução única para os esforços da administração pública. Dessa forma, ao invés de empregar técnicas econométricas, utilizou-se o fuzzyset Qualitative Comparative Analysis (fsQCA), o qual identifica diferentes caminhos possíveis para um resultado almejado. Em outras palavras, o fsQCA identifica diferentes combinações de condições 
(chamadas soluções) que simultaneamente levam ao resultado de sucesso, que, neste estudo, é a redução da transmissão da COVID-19.

As evidências empíricas identificam três caminhos principais consistentes com a redução da transmissão da COVID-19 nos estágios iniciais do surto. O primeiro caminho para evitar a propagação do vírus foi o estabelecimento de colaboração plural através de unidades públicas e envolvendo parceiros privados para compensar a falta de recursos especializados. Esse primeiro resultado é chamado de caminho da colaboração plural. O segundo caminho é a implementação de programas de auxílio governamentais pela colaboração dentro do setor público para superar a falta de recursos especializados e a vulnerabilidade social da população local. Este é o caminho da ação pública. Finalmente, o terceiro caminho depende de um sistema de saúde bem estruturado e a coordenação centralizada em uma unidade pública, chamado de caminho baseado em recursos.

\section{ADMINISTRAÇÃO PÚBLICA E AS REPOSTAS AO SURTO DA COVID-19}

Embora a COVID-19 seja ainda uma doença nova e com poucos parâmetros conhecidos, as comunidades médica e científica rapidamente chegaram a consensos sobre medidas práticas para reduzir sua transmissão e como reagir ao surto ${ }^{1}$. Até o momento, alguns princípios estão guiando os agentes públicos, incluindo: (1) isolamento de casos confirmados e suspeitos, bem como o acompanhamento de todos que tiveram contato com possíveis portadores do vírus (Hellewell et al., 2020); (ii) mobilização de recursos humanos e materiais de saúde, dado que a rápida propagação da doença leva a um grande número de internações e um subsequente colapso do sistema de saúde (Remuzzi \& Remuzzi, 2020); e (iii) quarentena ou distanciamento social generalizado para prevenir a propagação da doença e aliviar o sistema de saúde; isto é, achatar a curva de propagação do vírus (Lazzerini \& Putoto, 2020). Do ponto de vista da administração pública, esses princípios são convertidos em ações práticas, sob condições locais específicas.

Condições contextuais. Na literatura da Administração Pública, o contexto interage com as práticas gerenciais e influenciam o desempenho (O’Toole \& Meier, 2015). A disponibilidade de recursos no entorno é a característica do contexto chamada de munificência de recursos ambientais. Quando os recursos são encontrados em abundância, há um maior número de oportunidades e, assim, há efeito positivo no desempenho da organização (Andrews, 2009). No surto da COVID-19, mais especificamente, a disponibilidade de recursos de saúde é crítica não apenas para identificar e monitorar casos suspeitos, mas também para tratar os casos críticos da doença (Armocida et al., 2020; Ji et al., 2020).

Outra condição contextual relevante no surto da COVID-19 é a vulnerabilidade social da população local. Os problemas de saúde pública são frequentemente mais severos em locais onde grandes proporções da população moram em condições de vulnerabilidade (Ahmed, Ahmed, Pissarides, \& Stiglitz, 2020). Por exemplo, há um debate corrente na Inglaterra e nos EUA para investigar se minorias étnicas estão morrendo da COVID-19 em número desproporcionalmente maior que os brancos². Além disso, a população vulnerável reside em áreas densamente populosas e com infraestrutura pobre, o

\footnotetext{
${ }^{1}$ Organização Mundial da Saúde: todas as orientações técnicas sobre a COVID-19 pode ser encontrado aqui: https://www.who.int/ emergencies/diseases/novel-coronavirus-2019/technical-guidance

${ }^{2}$ Recuperado de https://www.theguardian.com/world/2020/apr/22/racial-inequality-in-britain-found-a-risk-factor-for-covid-19
} 
que prejudica a prevenção de doenças (Snyder, Marlow, Phuphanich, Riley, \& Maciel, 2016). Dessa forma, a vulnerabilidade social também pode afetar os resultados de políticas públicas para conter a propagação da COVID-19.

Ações da administração pública. A primeira resposta governamental para o surto da COVID-19 são restrições na movimentação de pessoas com o objetivo de diminuir a transmissão do vírus (Chen, Yang, Yang, Wang, \& Bärnighausen, 2020). Subsequentemente, a administração pública tem que endereçar impactos de segunda ordem do distanciamento social. Como mencionado, vulnerabilidade social pode ter um papel essencial durante o surto. A economia informal é significante no Brasil e a população mais pobre, com o distanciamento social, tem o fluxo de rendimentos interrompido abruptamente. Dessa forma, pode ser mais difícil manter as pessoas em casa na presença de vulnerabilidade social ${ }^{3}$, prejudicando a prevenção da disseminação da doença. Durante o surto da COVID-19, uma relevante ação pública é a provisão de programas de auxílio para atender as necessidades básicas da população vulnerável ${ }^{4}$.

Governança para as ações da administração pública. Mais recentemente, a perspectiva de um processo de elaboração de política pública unilateral está sendo crescentemente substituído por tomadas de decisão coletivas e envolvendo setores público e privado (Ansell \& Gash, 2007). Neste cenário, a administração pública tem que encontrar formas de alcançar colaborações entre múltiplas unidades através da colaboração dentro do setor público (Cabral \& Krane, 2018; Sedgwick, 2017). No entanto, as soluções não estão concentradas apenas dentro da burocracia pública. A colaboração com o setor privado é crítica para lidar com a complexidade do surto da COVID-19 (Lazzarini \& Musacchio, no prelo). As colaborações entre setores podem funcionar efetivamente por uma miríade de configurações (Lazzarini, Pongeluppe, Ito, Oliveira, \& Ovanessoff, no prelo). Por um lado, colaborações entre setores são eficientes sob condições de munificência de recursos e estabilidade do ambiente (Provan \& Milward, 1995; Raab, Mannak, \& Cambre, 2013). Por outro lado, enquanto o surto da COVID-19 não cria um ambiente estável, organizações baseadas em rede podem também responder eficientemente à situações de crises e desastres (Kapucu \& Garayev, 2011).

\section{DADOS E MÉTODOS}

Este é um estudo de casos múltiplos com municípios brasileiros enfrentando a COVID-19 nos 30 dias iniciais do surto. O benefício de um estudo de casos múltiplos baseia-se em dois fatores principais. Primeiro, ele permite encontrar padrões comuns em meio a diferentes observações, considerando-os deterministicamente e não probabilisticamente. Em outras palavras, todos os casos contribuem para melhorar nossa compreensão dos fenômenos (Bansal, Smith, \& Vaara, 2018; Kahwati et al., 2016). Segundo, a validade de vários estudos de caso baseia-se na seleção de casos que compartilham um conjunto semelhante de características ancoradas em construções teóricas. Além disso, a possibilidade de replicação da análise usando ocorrências semelhantes valida o esforço empírico (Eisenhardt, 1989; Pratt, Kaplan, \& Whittington, 2019).

\footnotetext{
${ }^{3}$ Recuperado de https://valor.globo.com/mundo/blog-do-fmi/post/2020/04/a-politica-economica-na-al-e-caribe-em-tempos-decovid-19.ghtml

${ }^{4}$ Recuperado de https://www.gov.br/casacivil/pt-br/assuntos/noticias/2020/abril/solicitar-auxilio-emergencial-de-r-600-coronaviruscovid-19
} 
Como são possíveis diferentes caminhos alternativos de sucesso e a natureza interativa das ações públicas, mecanismos de governança e fatores contextuais, utiliza-se o método fsQCA (Rihoux \& Lobe, 2009). O fsQCA aplica álgebra de conjuntos difusos para construir diferentes combinações de condições consistentes com um determinado resultado (Crilly, Zollo, \& Hansen, 2012; Fiss, 2007). Em outras palavras, o fsQCA mapeia os diferentes caminhos possíveis que levam a um resultado semelhante.

Processo de seleção de casos e conjunto de dados. Foram identificados os municípios brasileiros com pelo menos 30 dias desde o primeiro caso confirmado da COVID-19, até o dia 16 de abril de 2020. Essa data de corte determinou um conjunto de 52 municípios. Como os municípios encontravamse em diferentes estágios de enfrentamento do surto, foram consideradas apenas estatísticas e ações ocorridas nos primeiros 30 dias em cada município. O Quadro 1 fornece uma lista dos municípios selecionados. Abaixo, descreve-se o resultado e as condições que usamos na especificação do modelo.

\section{QUADRO 1 LISTA DE MUNICÍPIOS NO CONJUNTO DE DADOS}

\begin{tabular}{lll}
\hline & \multicolumn{1}{c}{ Nome do Município } & \\
Anápolis-GO & Fortaleza-CE & Porto Alegre-RS \\
Aquiraz-CE & Foz do lguaçu-PR & Porto Seguro-BA \\
Barra Mansa-RJ & Goiânia-GO & Prado-BA \\
Belo Horizonte-MG & Guarulhos-SP & Rancho Queimado-SC \\
Belo Jardim-PE & Ipatinga-MG & Recife-PE \\
Braço do Norte-SC & Jaboatão dos Guararapes-PE & Rio Branco-AC \\
Campo Bom-RS & Joinville-SC & Rio de Janeiro-RJ \\
Campo Grande-MS & Juiz de Fora-MG & Rio Verde-GO \\
Campo Largo-PR & Londrina-PR & Salvador-BA \\
Carapicuíba-SP & Maceió-AL & Santana de Parnaíba-SP \\
Caxias do Sul-RS & Manaus-AM & Santo André-SP \\
Cianorte-PR & Maringá-PR & São Bernardo do Campo-SP \\
Coronel Fabriciano-MG & Mauá-SP & São Caetano do Sul-SP \\
Curitiba-PR & Natal-RN & São Paulo-SP \\
Divinópolis-MG & Niterói-RJ & Sete Lagoas-MG \\
Feira de Santana-BA & Nova Lima-MG & Uberlândia-MG \\
Ferraz de Vasconcelos-SP & Patrocínio-MG & \\
Florianópolis-SC & Pinhais-PR & \\
\hline
\end{tabular}

Nota: A tabela A1 no apêndice fornece informações adicionais dos municípios. Fonte: Elaborado pelos autores.

Resultado: menor transmissão da COVID-19. O resultado é o número de casos confirmados da COVID-19 por 100 mil habitantes no município até o trigésimo dia após o primeiro caso confirmado da COVID-19. Foi utilizada a forma negada do resultado, o que significa que os municípios mais 
bem-sucedidos são aqueles com níveis mais baixos de casos confirmados. A fonte é o site "brasil. io", que é uma iniciativa independente e consolida dados diários das secretarias de saúde estaduais.

Munificência de recursos. A primeira condição contextual mede a disponibilidade de recursos para responder ao surto. Foi utilizado o número de médicos por 100 mil habitantes no município em janeiro de 2020 para capturar o tamanho do sistema de saúde em vigor. Também se mediu o número de leitos hospitalares na especialidade de pneumologia por 100 mil habitantes no município para avaliar os recursos especializados. Os dados estão disponíveis no site do DATASUS, que é um repositório de dados do Ministério da Saúde.

Vulnerabilidade social. Uma outra condição contextual está relacionada com a estrutura social do município. Foram coletados dados do índice de vulnerabilidade social para cada município, disponível no "Atlas da Vulnerabilidade Social", elaborado pelo Instituto de Pesquisa Econômica Aplicada (IPEA).

Programas de auxílio. Foram identificadas as ações públicas relacionadas a programas de auxílio com fontes de recursos provenientes dos municípios. Ao ler as leis municipais e os artigos de jornal, identificamos três tipos de programas: (i) fornecimento de refeições para estudantes de escolas públicas em casa; (ii) distribuição de cestas básicas; (iii) outros programas para reduzir impostos, crédito subsidiado para pequenas empresas ou oferecer assistência financeira diretamente. Além de fontes oficiais dos municípios, usamos o Google para procurar evidências de programas de ajuda em jornais. ${ }^{5}$

Colaboração com o setor público. Essa variável identifica a criação de entidades envolvendo múltiplas secretarias dentro da burocracia pública para lidar especificamente com o surto da doença, segundo fontes oficiais dos municípios e buscas nos jornais. ${ }^{6}$

Colaboração com o setor privado. Refere-se à presença de uma iniciativa relevante com a participação conjunta da prefeitura e de organizações externas ao setor público. As fontes também são leis municipais e buscas nos jornais. ${ }^{7}$

As medidas das variáveis relativas aos programas de auxílio e colaborações da prefeitura são influenciadas pelo julgamento do analista sobre o conteúdo da lei e dos artigos de jornal. Nesse processo, foram selecionadas políticas iniciadas em nível municipal, distribuídas pelas prefeituras, isto é, excluindo ações nos níveis estadual ou federal. Além disso, foram excluídas as iniciativas públicas pontuais ou as iniciativas do setor privado sem a participação das prefeituras ou apenas reconhecidas pelas prefeituras ${ }^{8}$.

Análise dos dados. A etapa inicial crítica do fsQCA é calibrar se o resultado ou uma condição está presente ou não em um caso. O Quadro A7 do apêndice descreve os critérios de calibragem para cada variável. Em seguida, de acordo com os critérios estabelecidos na literatura do fsQCA, após analisar a tabela verdade, adotou-se um limiar de consistência de 0,8 (Ragin, 2006; Schneider \& Wagemann, 2012). Também foi considerado um limiar de frequência de pelo menos um caso na solução, dada a pequena amostra (Rhioux \& Ragin, 2009). Por fim, foram relatadas as soluções intermediárias fornecidas pelo software fsQCA (Fiss, 2011; Misangyi \& Acharya, 2014).

Analisando a amostra em relação à ação pública, 26,9\% dos municípios não ofereceram nenhum auxílio governamental à população. As porcentagens daqueles que forneceram um, dois e três

\footnotetext{
${ }^{5}$ Nesta pesquisa, usamos o Google com a seguinte descrição em: "coronavírus $+<<$ município $>>$ + prefeitura + auxílio OU bolsa OU cesta básica". O Quadro A4 no apêndice descreve as evidências.

${ }^{6}$ Similarmente: coronavírus $+<<$ município $>>+$ prefeitura + comitê OU comissão OU gabinete OU centro de operações OU campanha OU convênio. O Quadro A5 no apêndice descreve as evidências.

${ }^{7}$ Similarmente: coronavírus + <<município >> + prefeitura + parceria OU colaboração OU campanha OU convênio OU empresários OU empresas OU ONG OU força-tarefa.

${ }^{8}$ As tabelas e quadros do A2 até o A6 no apêndice detalha o conteúdo das medidas de ação pública e colaboração, bem como indica as fontes.
} 
programas de ajuda, respectivamente, são 51,9\%, 19,2\% e 1,9\%. Verificando os mecanismos de governança, por sua vez, descobrimos que $50 \%$ das prefeituras usavam apenas colaboração no setor público, 7,7\% estabeleceram colaboração apenas com o setor privado e $25 \%$ criaram colaboração tanto no setor público quanto no setor privado. Assim, 17,3\% das prefeituras não tiveram colaboração. A tabela A8 no apêndice apresenta as estatísticas descritivas dos fatores contextuais.

\section{RESULTADOS}

O Quadro 2 apresenta os resultados da análise comparativa qualitativa, mostrando três soluções consistentes com a diminuição da transmissão da COVID-19 nos estágios iniciais do surto. Interpretamos os resultados considerando que "•" indica a presença de uma condição e " $\otimes$ " indica a ausência de uma condição. Os espaços em branco, no jargão da fsQCA, significam "não relevante”; isto é, a condição pode estar presente ou ausente na solução. Por exemplo, a solução la é caracterizada pela presença de colaboração no setor público e colaboração com o setor privado, bem como pela ausência de leitos hospitalares. Na primeira solução, a munificência de recursos em termos de médicos e vulnerabilidade social é uma condição "não relevante", o que significa que essas características podem estar presentes ou não para impedir a transmissão da COVID-19 nesta solução.

A solução $1 \mathrm{~b}$ tem uma ausência de todas as condições de munificência de recursos e a presença de vulnerabilidade social. Esses fatores contextuais interagem com a presença de programas de auxílio e com a presença colaboração do governo no setor público. Ainda na solução 1b, a colaboração com o setor privado não é uma condição relevante. Por fim, a solução 2 tem presença de apenas duas dimensões da munificência de recursos, enquanto todas as ações públicas e condições de governança estão ausentes.

\section{QUADRO 2 RESULTADOS DO QCA SOBRE AS COMBINAÇÕES DE CONDIÇÕES PARA EVITAR A TRANSMISSÃO DA COVID-19 EM SEUS ESTÁGIOS INICIAIS}

\begin{tabular}{|c|c|c|c|}
\hline & & luçõo & \\
\hline & $1 \mathrm{a}$ & $1 \mathrm{~b}$ & 2 \\
\hline Condições contextuais iniciais & & & \\
\hline - Munificência de recursos (médicos) & & $\otimes$ & $\bullet$ \\
\hline - Munificência de recursos (leitos) & $\otimes$ & $\otimes$ & 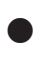 \\
\hline - Vulnerabilidade social & & ○ & \\
\hline Governança e Ação Pública & & & \\
\hline - Programas de auxílio & $\otimes$ & $\bullet$ & $\otimes$ \\
\hline - Colaboraçõa dentro do setor público & $\bullet$ & 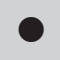 & $\otimes$ \\
\hline - Colaboração com o setor privado & 0 & & $\otimes$ \\
\hline
\end{tabular}




\begin{tabular}{lccc} 
& \multicolumn{3}{c}{ Soluções } \\
& $1 \mathbf{a}$ & $1 \mathbf{b}$ & $\mathbf{2}$ \\
Consistência & 0,845 & 0,867 & 0,873 \\
Cobertura bruta & 0,141 & 0,166 & 0,090 \\
Cobertura única & 0,090 & 0,115 & 0,090 \\
Número de casos & 4 & 2 & 3 \\
& Belo Jardim-PE & & Divinópolis-MG \\
Caritiba-PR & Campo Bom-RS & Belo Horizonte-MG \\
& Mauá-SP & Pinhais-PR & \\
Rio Verde-GO & & 0,843 -Go \\
Consistência geral da solução & & 0,345 & \\
\hline
\end{tabular}

Notas: Círculos pretos (“”) indicam a presença de uma condição e círculos abertos (“®”) indicam sua ausência. Os espaços em branco indicam "não se importam”; isto é, a condição não é relevante para essa configuração específica.

Fonte: Elaborado pelos autores.

Antes da discussão, é importante comentar sobre os procedimentos de distanciamento social adotados nos municípios. Apesar de sua importância, as leis de distanciamento social não foram exploradas no modelo porque essa era uma decisão tomada principalmente no nível estadual. Segundo, todos os municípios adotaram leis de distanciamento social e parece razoável supor que o distanciamento social é uma prática presente em toda a amostra. No entanto, é possível rastrear quantos dias foram necessários desde o primeiro caso até o fechamento de lojas e escolas em cada município. Em geral, comparando o número de dias por solução, apenas os municípios da solução $1 \mathrm{~b}$ parecem levar mais tempo para fechar as escolas do que o comportamento médio da amostra. O Quadro A9 no apêndice resume a análise9.

\section{DISCUSSÃO}

Contribuições para elaboração de políticas públicas no nível municipal. Os resultados demonstram que as opções de ação pública são limitadas por condições contingentes no ambiente do município e existem três caminhos possíveis para a formulação de políticas. A Figura 1 é uma representação visual do processo de tomada de decisão com base nos resultados ${ }^{10}$. Os resultados podem servir de referência para os tomadores de decisão nas administrações municipais lidarem com o estágio inicial do surto da COVID-19.

\footnotetext{
${ }^{9}$ No apêndice, o quadro A10, a tabela A11 e a Figura A12 analisam a associação entre soluções e outras características de caso. Solução $1 \mathrm{~b}$ apresenta associação com região sul e pequenas cidades.

${ }^{10}$ Durante o processo de revisão, aproveitamos a oportunidade para realizar uma verificação de robustez. Na figura A13 do apêndice, é possível ver que os municípios fora de nossas soluções apresentaram uma propagação mais rápida da COVID-19 em comparação com os municípios participantes de nossas soluções.
} 


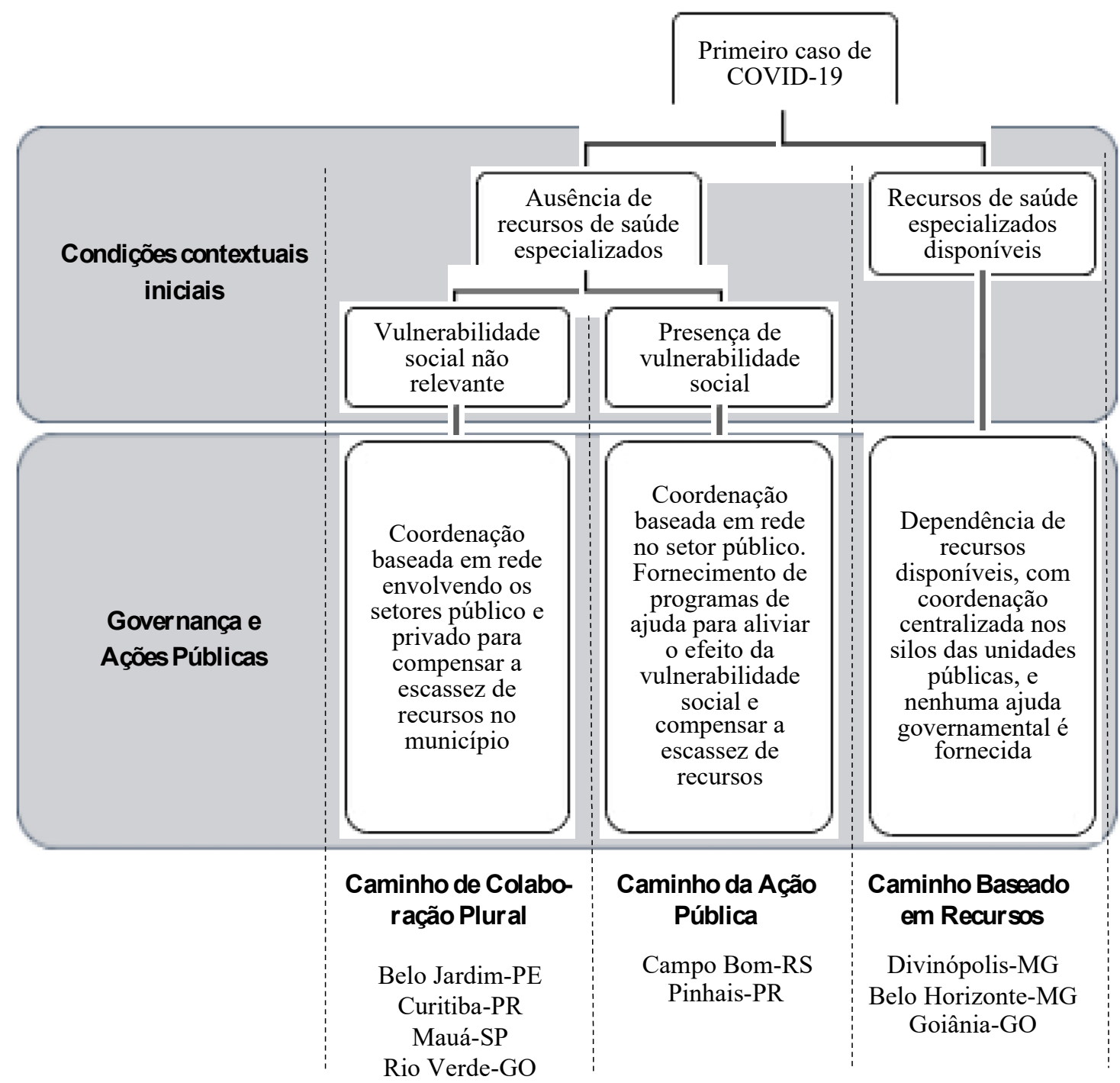

Nota: a figura tem como objetivo ilustrar os resultados baseados na interpretação das soluções de QCA. Portanto, o objetivo aqui é facilitar a interpretação, mas não necessariamente ser exaustivo.

Fonte: Elaborada pelos autores.

O primeiro caminho (solução la) é limitado pela falta de recursos especializados; portanto, para evitar a disseminação da COVID-19, o governo local deve desenvolver uma colaboração plural nos setores público e privado. Um exemplo é uma parceria público-privada entre a prefeitura de Mauá, no estado de São Paulo, e um hospital privado para aumentar o número de leitos hospitalares disponíveis no sistema público de saúde. Esse caminho mostra que, na falta de recursos, as colaborações podem ser a melhor estratégia para o governo local. Além disso, a prefeitura de Mauá criou o chamado "Centro Especializado de Combate ao Coronavírus", integrando diferentes secretarias municipais. Dessa forma, este é o chamado caminho de colaboração plural. O segundo caminho (solução 1b) é 
caracterizado pela falta de recursos disponíveis e pela ameaça da vulnerabilidade social. A melhor estratégia para o governo local é planejar ações públicas pela provisão de auxílios e a coordenação com outras unidades públicas para atenuar a disseminação da COVID-19. Por exemplo, a prefeitura de Pinhais, no estado do Paraná, forneceu ajuda financeira a trabalhadores informais da coleta de lixo reciclável. Portanto, este é o chamado caminho da ação pública. Finalmente, o terceiro caminho (solução 2) baseia-se em um sistema de saúde bem estruturado. Nesse caso, a presença de recursos de saúde garante respostas bem-sucedidas contra a disseminação da COVID-19 e é chamado de caminho baseado em recursos.

Contribuições para a literatura da Administração Pública. Comparando as soluções $1(1 \mathrm{a}+1 \mathrm{~b})$ e 2, há um intercâmbio entre munificência de recursos e governança baseada em rede. A munificência de recursos interage com a falta de organizações baseadas em rede, o que contradiz os principais modelos da literatura em Administração Pública (p. ex., Provan \& Milward, 1995), mas apoia os resultados da tomada de decisão colaborativa no gerenciamento de emergências (p. ex., Kapucu \& Garayev, 2011). Assim, essas descobertas contribuem para um tópico ainda pouco estudado de gestão de crises e desastres no campo da Administração Pública. O papel da vulnerabilidade social nas explicações de estratégias emergenciais em problemas de saúde pública pode fornecer novas ideias para esse debate.

Limitações. Levando em consideração as características do conjunto de dados e as escolhas metodológicas, os resultados não são generalizáveis. Em vez de generalização, os resultados permitem a elaboração de uma teoria de médio alcance aplicada ao nível municipal brasileiro durante os estágios iniciais do surto no país. Além disso, a solução $1 \mathrm{~b}$ destaca a interação entre a vulnerabilidade social e os programas de auxílio do governo. No entanto, essa solução também é caracterizada por sua localização na região sul do Brasil e pelo pequeno porte do município. Portanto, argumentar que os programas de auxílio são uma resposta à vulnerabilidade social é ainda frágil, pois a solução la mostra uma situação "não relevante" para a vulnerabilidade social na ausência de ajuda do governo. 


\section{REFERÊNCIAS}

Ahmed, F., Ahmed, N., Pissarides, C., \& Stiglitz, J. (2020, 02 de abril). Why inequality could spread COVID-19. The Lancet Public Health, 5(5), e240. Recuperado de https://doi.org/10.1016/S24682667(20)30085-2

Andrews, R. (2009). Organizational Task Environments and Performance: An Empirical Analysis. International Public Management Journal, 12(1), 1-23. Recuperado de https://doi. org/10.1080/10967490802646813

Ansell, C., \& Gash, A. (2007). Collaborative Governance in Theory and Practice. Journal of Public Administration Research and Theory, 18(4), 543-571. Recuperado de https://doi.org/10.1093/ jopart/mum032

Armocida, B., Formenti, B., Ussai, S., Palestra, F., \& Missoni, E. (2020). The Italian health system and the COVID-19 challenge. The Lancet Public Health, 5(5), e253. Recuperado de https://doi.org/10.1016/ S2468-2667(20)30074-8

Bansal, P., Smith, W. K., \& Vaara, E. (2018). From the Editors: New Ways of Seeing through Qualitative Research. Academy of Management Journal, 61(4), 1189-1195. Recuperado de https://doi.org/10.1016/ B978-0-444-56336-1.50013-8

Cabral, S., \& Krane, D. (2018). Civic festivals and collaborative governance. International Review of Administrative Sciences, 84(1), 185-205. Recuperado de https://doi.org/10.1177/0020852315615196

Chen, S., Yang, J., Yang, W., Wang, C., \& Bärnighausen, T. (2020). COVID-19 control in China during mass population movements at New Year. The Lancet, 395(10226), 764-766. Recuperado de https://doi. org/10.1016/S0140-6736(20)30421-9

Crilly, D., Zollo, M., \& Hansen, M. T. (2012). Faking It or Muddling Through? Understanding Decoupling in Response to Stakeholder Pressures. Academy of Management Journal, 55(6), 1429-1448. Recuperado de https://doi.org/10.5465/amj.2010.0697

Eisenhardt, K. M. (1989). Building Theories from Case Study Research. Academy of Management Review, 14(4), 532-550. Recuperado de https://doi. org/10.5465/AMR.1989.4308385

Fiss, P. C. (2007). A Set-Theoretic Approach To Organizational Configurations. Academy of Management Review, 32(4), 1180-1198.

Fiss, P. C. (2011). Building better causal theories: A fuzzy set approach to typologies in organization research. Academy of Management Journal, 54(2), 393-420.

Hellewell, J., Abbott, S., Gimma, A., Bosse, N. I., Jarvis, C. I., Russell, T. W., ... van Zandvoort, K. (2020). Feasibility of controlling COVID-19 outbreaks by isolation of cases and contacts. The Lancet Global Health, 8(4), e488-e496. Recuperado de https://doi.org/10.1016/S2214-109X(20)30074-7

Ji, Y., Ma, Z., Peppelenbosch, M. P., \& Pan, Q. (2020). Potential association between COVID-19 mortality and healthcare resource availability. The Lancet Global Health, 8(4), e480. Recuperado de https:// doi.org/10.1016/S2214-109X(20)30068-1

Kahwati, L., Jacobs, S., Kane, H., Lewis, M., Viswanathan, M., \& Golin, C. E. (2016). Using qualitative comparative analysis in a systematic review of a complex intervention. Systematic Reviews, 5, 82. Recuperado de https://doi.org/10.1186/ s13643-016-0256-y

Kapucu, N., \& Garayev, V. (2011). Collaborative Decision-Making in Emergency and Disaster Management. International Journal of Public Administration, 34(6), 366-375. Recuperado de https://doi.org/10.1080/01900692.2011.561477

Lazzarini, S. G., \& Musacchio, A. (No prelo). Leviathan as a partial cure? opportunities and pitfalls of using the state-owned apparatus to respond to the Covid-19 crisis. Revista de Administração Pública, Early view: A resposta da administração pública brasileira aos desafios da pandemia, 1-25.

Lazzarini, S. G., Pongeluppe, L. S., Ito, N. C., Oliveira, F. de M., \& Ovanessoff, A. (No prelo). Public Capacity, Plural Forms of Collaboration, and the Performance of Public Initiatives: A Configurational Approach. Journal of Public Administration Research and Theory, muaa007.

Lazzerini, M., \& Putoto, G. (2020). COVID-19 in Italy: momentous decisions and many uncertainties. The Lancet Global Health, 8(5), e641-e642. Recuperado de https://doi.org/10.1016/S2214-109X(20)30110-8

Melo, C., \& Cabral, S. (No prelo). Pandemics and Communicaton: A Randomized Control Trial Assessment. Revista de Administração Pública, Early view: A resposta da administração pública brasileira aos desafios da pandemia, 1-26.

Misangyi, V. F., \& Acharya, A. G. (2014). Substitutes or Complements? A Configurational Examination of Corporate Governance Mechanisms. Academy of Management Journal, 57(6), 1681-1705. Recuperado de https://doi.org/10.5465/amj.2012.0728 
O’Toole, L. J., \& Meier, K. J. (2015). Public Management, Context, and Performance: In Quest of a More General Theory. Journal of Public Administration Research and Theory, 25(1), 237256. Recuperado de https://doi.org/10.1093/jopart/ muu011

Pratt, M. G., Kaplan, S., \& Whittington, R. (2020). Editorial Essay: The Tumult over Transparency: Decoupling Transparency from Replication in Establishing Trustworthy Qualitative Research. Administrative Science Quarterly, 65(1), 1-19. Recuperado de https://doi. org/10.1177/0001839219887663

Provan, K. G., \& Milward, H. B. (1995). A Preliminary Theory of Interorganizational Network Effectiveness: A Comparative Study of Four Community Mental Health Systems. Administrative Science Quarterly, 40(1), 1-33. Recuperado de https://doi.org/10.2307/2393698

Raab, J., Mannak, R. S., \& Cambre, B. (2013). Combining Structure, Governance, and Context: A Configurational Approach to Network Effectiveness Jorg Raab. Journal of Public Administration Research and Theory, 25(2), 479-511. Recuperado de https:// doi.org/10.1093/jopart/mut039

Ragin, C. C. (2006). Set Relations in Social Research: Evaluating Their Consistency and Coverage. Political Analysis, 14(3), 291-310. Recuperado de https://doi. org/10.1093/pan/mpj019

Remuzzi, A., \& Remuzzi, G. (2020). COVID-19 and Italy: what next? The Lancet, 395(10231), 1225-1228.
Recuperado de https://doi.org/10.1016/S01406736(20)30627-9

Rhioux, B., \& Ragin, C. C. (2009). Configurational Comparative Methods Qualitative Comparative Analysis (QCA) and Related Techniques. Thousand Oaks, CA: Sage.

Rihoux, B., \& Lobe, B. (2009). The Case for Qualitative Comparative Analysis (QCA): Adding Leverage for Thick Cross-Case Comparison. In D. Byrne \& C. C. Ragin (Eds.), The SAGE Handbook of Case-Based Methods (pp. 222-242). London, UK: SAGE. Recuperado de https://doi. org/10.4135/9781446249413.n13

Schneider, C. Q., \& Wagemann, C. (2012). SetTheoretic Methods for the Social Science. A Guide to Qualitative Comparative Analysis. New York, NY: Cambridge University Press. Recuperado de https:// doi.org/10.1017/CBO9781107415324.004

Sedgwick, D. (2017). Building collaboration: Examining the relationship between collaborative processes and activities. Journal of Public Administration Research and Theory, 27(2), 236252. Recuperado de https://doi.org/10.1093/jopart/ muw057

Snyder, R. E., Marlow, M. A., Phuphanich, M. E., Riley, L. W., \& Maciel, E. L. N. (2016). Risk factors for differential outcome following directly observed treatment (DOT) of slum and non-slum tuberculosis patients: a retrospective cohort study. BMC Infectious Diseases, 16(1), 1-7. Recuperado de https://doi. org/10.1186/s12879-016-1835-1

\section{Nobuiuki C. Ito}

https://orcid.org/0000-0001-5001-7204

Doutor em Administração (FEA/USP); Professor, Ibmec São Paulo. E-mail: nobuiuki.ito@ibmec.edu.br

\section{Leandro S. Pongeluppe}

https://orcid.org/0000-0001-6195-4455

Doutorando em Administração Estratégica (University of Toronto).E-mail: l.pongeluppe@rotman.utoronto.ca 


\section{APÊNDICE}

\section{TABELA A1 LISTA DE MUNICÍPIOS NO CONJUNTO DE DADOS E OUTRAS INFORMAÇÕES RELEVANTES}

\begin{tabular}{|c|c|c|c|c|}
\hline Município & $\begin{array}{l}\text { Data do primeiro } \\
\text { caso confirmado da } \\
\text { COVID-19 }\end{array}$ & $\begin{array}{l}\text { Data do trigésimo dia } \\
\text { depois do primeiro } \\
\text { caso da COVID-19 } \\
\text { confirmado }\end{array}$ & $\begin{array}{l}\text { Número de casos } \\
\text { confirmados da } \\
\text { COVID-10 por } 100 \\
\text { mil habitantes no } \\
\text { trigésimo dia }\end{array}$ & $\begin{array}{c}\text { Taxa de óbitos } \\
\text { da COVID-19 no } \\
\text { trigésimo dia }\end{array}$ \\
\hline Anápolis-G0 & 16-Mar-2020 & 14-Abr-2020 & 5,2 & $0 \%$ \\
\hline Aquiraz-CE & 16-Mar-2020 & 14-Abr-2020 & 37,4 & $0 \%$ \\
\hline Barra Mansa-RJ & 5-Mar-2020 & 3-Abr-2020 & 1,6 & $0 \%$ \\
\hline Belo Horizonte-MG & 16-Mar-2020 & 14-Abr-2020 & 14,8 & $2 \%$ \\
\hline Belo Jardim-PE & 17-Mar-2020 & 15-Abr-2020 & 2,6 & $0 \%$ \\
\hline Braço do Norte-SC & 15-Mar-2020 & 13-Abr-2020 & 74,7 & $0 \%$ \\
\hline Campo Bom-RS & 10-Mar-2020 & 8-Abr-2020 & 6,0 & $0 \%$ \\
\hline Campo Grande-MS & 14-Mar-2020 & 12-Abr-2020 & 5,7 & $0 \%$ \\
\hline Campo Largo-PR & 17-Mar-2020 & 15-Abr-2020 & 9,1 & $17 \%$ \\
\hline Carapicuíba-SP & 14-Mar-2020 & 12-Abr-2020 & 8,2 & $6 \%$ \\
\hline Caxias do Sul-RS & 12-Mar-2020 & 10-Abr-2020 & 6,7 & $0 \%$ \\
\hline Cianorte-PR & 12-Mar-2020 & 10-Abr-2020 & 15,7 & $8 \%$ \\
\hline Coronel Fabriciano-MG & 17-Mar-2020 & 15-Abr-2020 & 2,7 & $0 \%$ \\
\hline Curitiba-PR & 12-Mar-2020 & 10-Abr-2020 & 13,0 & $2 \%$ \\
\hline Divinópolis-MG & 8-Mar-2020 & 6-Abr-2020 & 6,3 & $0 \%$ \\
\hline Feira de Santana-BA & 6-Mar-2020 & 4-Abr-2020 & 3,7 & $0 \%$ \\
\hline Ferraz de Vasconcelos-SP & 12-Mar-2020 & 10-Abr-2020 & 18,0 & $0 \%$ \\
\hline Florianópolis-SC & 12-Mar-2020 & 10-Abr-2020 & 33,3 & $2 \%$ \\
\hline Fortaleza-CE & 16-Mar-2020 & 14-Abr-2020 & 67,2 & $5 \%$ \\
\hline Foz do Iguaçu-PR & 18-Mar-2020 & 16-Abr-2020 & 13,9 & $0 \%$ \\
\hline Goiânia-G0 & 12-Mar-2020 & 10-Abr-2020 & 7,2 & $5 \%$ \\
\hline Guarulhos-SP & 17-Mar-2020 & 15-Abr-2020 & 18,3 & $9 \%$ \\
\hline Ipatinga-MG & 12-Mar-2020 & 10-Abr-2020 & 1,9 & $0 \%$ \\
\hline Jaboatão dos Guararapes-PE & 17-Mar-2020 & 15-Abr-2020 & 14,7 & $10 \%$ \\
\hline Joinville-SC & 13-Mar-2020 & 11-Abr-2020 & 8,8 & $2 \%$ \\
\hline Juiz de Fora-MG & 14-Mar-2020 & 12-Abr-2020 & 10,5 & $2 \%$ \\
\hline Londrina-PR & 17-Mar-2020 & 15-Abr-2020 & 13,0 & $5 \%$ \\
\hline
\end{tabular}


RAP | 0 surto da COVID-19 e as respostas da administração municipal: munificência de recursos, vulnerabilidade social e eficácia de ações públicas

\begin{tabular}{|c|c|c|c|c|}
\hline Município & $\begin{array}{l}\text { Data do primeiro } \\
\text { caso confirmado da } \\
\text { COVID-19 }\end{array}$ & $\begin{array}{l}\text { Data do trigésimo dia } \\
\text { depois do primeiro } \\
\text { caso da COVID-19 } \\
\text { confirmado }\end{array}$ & $\begin{array}{l}\text { Número de casos } \\
\text { confirmados da } \\
\text { COVID-10 por } 100 \\
\text { mil habitantes no } \\
\text { trigésimo dia }\end{array}$ & $\begin{array}{l}\text { Taxa de óbitos } \\
\text { da COVID-19 no } \\
\text { trigésimo dia }\end{array}$ \\
\hline Maceió-AL & 8-Mar-2020 & 6-Abr-2020 & 2,2 & $9 \%$ \\
\hline Manaus-AM & 13-Mar-2020 & $11-A b r-2020$ & 42,7 & $5 \%$ \\
\hline Maringá-PR & 18-Mar-2020 & 16-Abr-2020 & 7,6 & $16 \%$ \\
\hline Mauá-SP & 16-Mar-2020 & 14-Abr-2020 & 11,0 & $2 \%$ \\
\hline Natal-RN & 12-Mar-2020 & 10-Abr-2020 & 13,2 & $3 \%$ \\
\hline Niterói-RJ & 12-Mar-2020 & $10-A b r-2020$ & 22,8 & $4 \%$ \\
\hline Nova Lima-MG & 17-Mar-2020 & 15-Abr-2020 & 46,4 & $0 \%$ \\
\hline Patrocínio-MG & 14-Mar-2020 & $12-A b r-2020$ & 6,6 & $0 \%$ \\
\hline Pinhais-PR & 17-Mar-2020 & 15-Abr-2020 & 9,8 & $8 \%$ \\
\hline Porto Alegre-RS & 11-Mar-2020 & 9-Abr-2020 & 20,4 & $2 \%$ \\
\hline Porto Seguro-BA & 16-Mar-2020 & 14-Abr-2020 & 7,4 & $0 \%$ \\
\hline Prado-BA & 17-Mar-2020 & 15-Abr-2020 & 14,2 & $0 \%$ \\
\hline Rancho Queimado-SC & 14-Mar-2020 & $12-A b r-2020$ & 69,5 & $0 \%$ \\
\hline Recife-PE & 12-Mar-2020 & 10-Abr-2020 & 25,1 & $8 \%$ \\
\hline Rio Branco-AC & 17-Mar-2020 & 15-Abr-2020 & 18,7 & $4 \%$ \\
\hline Rio de Janeiro-RJ & 6-Mar-2020 & 4-Abr-2020 & 14,6 & $4 \%$ \\
\hline Rio Verde-G0 & 12-Mar-2020 & 10-Abr-2020 & 4,7 & $0 \%$ \\
\hline Salvador-BA & 13-Mar-2020 & $11-A b r-2020$ & 12,4 & $3 \%$ \\
\hline Santana de Parnaíba-SP & 7-Mar-2020 & 5-Abr-2020 & 17,2 & $0 \%$ \\
\hline Santo André-SP & 16-Mar-2020 & 14-Abr-2020 & 22,3 & $3 \%$ \\
\hline São Bernardo do Campo-SP & 16-Mar-2020 & 14-Abr-2020 & 24,0 & $5 \%$ \\
\hline São Caetano do Sul-SP & 16-Mar-2020 & 14-Abr-2020 & 47,8 & $4 \%$ \\
\hline São Paulo-SP & 25-Feb-2020 & 25-Mar-2020 & 5,9 & $6 \%$ \\
\hline Sete Lagoas-MG & 17-Mar-2020 & 15-Abr-2020 & 1,3 & $0 \%$ \\
\hline Uberlândia-MG & 17-Mar-2020 & 15-Abr-2020 & 8,8 & $7 \%$ \\
\hline
\end{tabular}

Fonte: Elaborada pelos autores. 
RAP | 0 surto da COVID-19 e as respostas da administração municipal: munificência de recursos, vulnerabilidade social e eficácia de ações públicas

\section{QUADRO A2 FONTE DOS DADOS QUALITATIVOS}

\section{Fontes dos dados qualitativos por município}

\section{Anápolis-G0}

https://www.jornalopcao.com.br/ultimas-noticias/roberto-naves-divulga-acoes-de-prevencao-ao-novo-coronavirus-emanapolis-241579/

https://sagresonline.com.br/noticias/saude-e-ciencias/100388-prefeitura-de-anapolis-decreta-situacao-de-emergenciapor-causa-do-novo-coronavirus

https://portal6.com.br/2020/04/03/decreto-de-calamidade-publica-em-anapolis-e-aprovado-pela-camara-municipal/ http://www.diario.anapolis.go.gov.br:8124/dowebans/page/diarioOficial.jsf

http://g1.globo.com/goias/videos/tttodos-os-videos/v/comercio-em-anapolis-deve-fechar-para-evitar-disseminacao-docoronavirus/8408695/

https://portal6.com.br/2020/04/18/geolab-doa-respiradores-para-ajudar-no-combate-ao-coronavirus-em-anapolis/ https://portal6.com.br/2020/04/18/cestas-basicas-da-prefeitura-de-anapolis-ja-estao-sendo-entregues-as-familias/ https://portal6.com.br/2020/04/04/familias-carentes-em-anapolis-poderao-solicitar-cestas-basicas-por-whatsapp/

\section{Aquiraz-CE}

https://epoca.globo.com/brasil/cidade-do-ceara-tem-escalada-de-coronavirus-apos-propagacao-em-comunidadecatolica-24345034

http://www.aquiraz.ce.gov.br/aviso-2/

http://www.aquiraz.ce.gov.br/governo-municipal-inaugura-nesta-quinta-feira-16-hospital-de-campanha/ http://www.aquiraz.ce.gov.br/refis-2/

https://www.opovo.com.br/noticias/ceara/iguatu/2020/04/16/coronavirus--aquiraz-inaugura-primeiro-hospital-decampanha-no-ceara.html

http://www.aquiraz.ce.gov.br/coronavirus-cestas-basicas-sao-distribuidas-no-municipio/ https://www.facebook.com/PrefeituraMunicipaldeAquiraz

\section{Barra Mansa-RJ}

https://diariodovale.com.br/tempo-real/barra-mansa-suspende-temporariamente-aulas-a-partir-de-segunda-dia-16/ https://exame.abril.com.br/brasil/mais-de-60-municipios-do-rio-entram-em-calamidade-publica-por-coronavirus/ https://diariodovale.com.br/politica/rodrigo-drable-fecha-comercio-em-barra-mansa/ http://barramansa.rj.gov.br/index.php/imprensa/noticias/1901-parceria-entre-prefeitura-e-iniciativa-privada-possibilita-adistribuicao-de-refeicoes-em-comunidades-carentes-de-barra-mansa http://www.barramansa.rj.gov.br/index.php/imprensa/noticias/1889-coronavirus-prefeitura-de-barra-mansa-orientapopulacao-sobre-distribuicao-de-cestas-basicas

\section{Belo Horizonte-MG}

http://portal6.pbh.gov.br/dom/iniciaEdicao.do?method=DetalheArtigo\&pk=1226967

http://portal6.pbh.gov.br/dom/iniciaEdicao.do?method=DetalheArtigo\&pk=1227069

http://portal6.pbh.gov.br/dom/iniciaEdicao.do?method=DetalheArtigo\&pk=1227534 


\section{Fontes dos dados qualitativos por município}

https://prefeitura.pbh.gov.br/smasac/cestas-basicas-para-familias-de-alunos-da-rede-municipal-de-educacao https://g1.globo.com/mg/minas-gerais/noticia/2020/03/31/coronavirus-escolas-publicas-estudam-alternativas-pararepor-aulas-particulares-aderem-ao-ensino-online-em-minas.ghtml

https://g1.globo.com/mg/minas-gerais/noticia/2020/03/24/coronavirus-cerca-de-150-mil-familias-de-bh-vao-recebercestas-basicas-da-prefeitura.ghtml

https://g1.globo.com/mg/minas-gerais/noticia/2020/04/01/coronavirus-cobranca-de-impostos-municipais-acomerciantes-e-suspensa-em-bh.ghtml

https://www.em.com.br/app/noticia/gerais/2020/03/19/interna_gerais,1130618/coronavirus-pbh-adia-cobranca-deimpostos-para-nao-sufocar-empresas.shtml

\section{Belo Jardim-PE}

https://belojardim.pe.gov.br/portal-transparencia/visualizar/index/legislacoes/2020-03-23-191313/decreto-n-18calamidade-publica-20200323151108.pdf

https://belojardim.pe.gov.br/portal-transparencia/visualizar/index/legislacoes/2020-03-21-000053/decreto-n-17covid-19-20200320203455.pdf

https://belojardim.pe.gov.br/portal-transparencia/visualizar/index/legislacoes/2020-03-21-000053/decreto-n-17covid-19-20200320203455.pdf

https://www.facebook.com/pg/PMBJOficial/posts/

https://www.bj1.com.br/empresarios-unem-forcas-e-dao-inicio-a-uma-acao-de-solidariedade-pela-populacao-de-pe/

\section{Braço do Norte-SC}

https://static.fecam.net.br/uploads/591/arquivos/1738029_Diario_Oficial_do_dia_18032020.pdf https://static.fecam.net.br/uploads/591/arquivos/1740187_I_Diario_Oficial_do_dia_20032020.pdf http://www.engeplus.com.br/noticia/geral/2020/prefeito-de-braco-do-norte-suspende-aulas-e-eventos-no-municipio https://static.fecam.net.br/uploads/591/arquivos/1744234_Diario_Oficial_do_dia_31032020.pdf https://notisul.com.br/geral/acao-bn-disponibilizara-10-tonelada-alimentos-para-familias-carentes-coronavirus/ https://www.bracodonorte.sc.gov.br/noticias/index/ver/codMapaltem/14640/codNoticia/610527

\section{Campo Bom-RS}

https://www.campobom.rs.gov.br/pt-br/prefeitura-de-campo-bom-distribui-500-kits-de-alimentos-para-alunos-da-redemunicipal

https://leismunicipais.com.br/a/rs/c/campo-bom/decreto/2020/679/6783/decreto-n-6783-2020-dispoe-sobredecretacao-de-emergencia-e-medidas-temporarias-de-prevencao-ao-contagio-pelo-covid-19-novo-coronavirus-noambito-do-municipio-de-campo-bom-no-que-se-refere-ao-funcionamento-de-restaurantes-bares-casas-noturnastemplos-religiosos-dentre-outros

https://leismunicipais.com.br/a/rs/c/campo-bom/decreto/2020/679/6783/decreto-n-6783-2020-dispoe-sobredecretacao-de-emergencia-e-medidas-temporarias-de-prevencao-ao-contagio-pelo-covid-19-novo-coronavirus-noambito-do-municipio-de-campo-bom-no-que-se-refere-ao-funcionamento-de-restaurantes-bares-casas-noturnastemplos-religiosos-dentre-outros?q=covid-19

https://www.campobom.rs.gov.br/pt-br/prefeitura-de-campo-bom-triplica-distribuicao-de-cestas-basicas 


\section{Fontes dos dados qualitativos por município}

https://leismunicipais.com.br/a/rs/c/campo-bom/decreto/2020/679/6781/decreto-n-6781-2020-dispoe-sobre-medidastemporarias-de-prevencao-ao-contagio-pelo-covid-19-novo-coronavirus-no-ambito-do-municipio-de-campo-bom?q=covid-19 https://www.campobom.rs.gov.br/pt-br/prefeitura-de-campo-bom-triplica-distribuicao-de-cestas-basicas https://www.campobom.rs.gov.br/pt-br/prefeitura-higieniza-locais-publicos-para-prevenir-coronavirus https://www.campobom.rs.gov.br/pt-br/coronavirus-campo-bom-cria-comite-publico-privado-para-gerenciar-crise https://www.campobom.rs.gov.br/pt-br/mais-uma-semana-de-solidariedade-no-combate-ao-coronavirus-em-campo-bom https://www.campobom.rs.gov.br/pt-br/tag/noticias?page=1

https://www.campobom.rs.gov.br/pt-br/mais-de-1600-atendimentos-na-central-de-informacoes-sobre-0-coronavirus https://www.jornalnh.com.br/cotidiano/blogs/bom_exemplo/2020/04/18/campanha--eucrioeuuso-vai-mostrar-mascarascriativas-em-campo-bom.html

https://www.jornalvs.com.br/noticias/especial_coronavirus/2020/04/09/prefeitura-de-campo-bom-busca-costureirasvoluntarias-para-produzir-25-mil-mascaras.html

https://www.campobom.rs.gov.br/pt-br/coronavirus-prefeitura-adquire-seis-respiradores-hospitalares

https://www.jornalvs.com.br/noticias/especial_coronavirus/2020/03/26/prefeitura-de-campo-bom-compra-1-mil-kits-detestagem-do-novo-coronavirus.html

\section{Campo Grande-MS}

https://g1.globo.com/ms/mato-grosso-do-sul/noticia/2020/03/15/para-prevenir-o-coronavirus-prefeitura-de-campogrande-suspende-as-aulas-de-escolas-e-creches-por-15-dias.ghtml

https://www.campograndenews.com.br/cidades/capital/prefeitura-manda-comercio-e-casas-noturnas-fecharem-asportas-contra-coronavirus

http://www.campogrande.ms.gov.br/cgnoticias/noticias/prefeitura-vai-entregar-kit-merenda-para-20-mil-alunos-doprograma-bolsa-familia/

http://www.campogrande.ms.gov.br/cgnoticias/noticias/prefeitura-cria-comite-municipal-de-enfrentamento-e-prevencaoa-covid-19/

http://g1.globo.com/mato-grosso-do-sul/videos/t/todos-os-videos/v/campo-grande-decreta-estado-de-emergencia-parao-novo-coronavirus/8410785/

https://www.campograndenews.com.br/cidades/capital/hospital-de-campanha-da-cassems-contra-coronavirus-comecaa-funcionar-na-segunda

http://www.campogrande.ms.gov.br/cgnoticias/noticias/prefeitura-declara-situacao-de-emergencia-em-campo-grande/ http://www.campogrande.ms.gov.br/cgnoticias/galerias/utr/

http://www.campogrande.ms.gov.br/cgnoticias/noticias/prefeitura-entrega-cestas-basicas-as-familias-de-autonomosque-prestam-servico-na-utr/

http://www.campogrande.ms.gov.br/cgnoticias/noticias/decreto-abre-caminho-para-reabertura-dos-shoppings-emantem-suspensas-aulas-e-eventos-com-aglomeracao/

http://www.campogrande.ms.gov.br/cgnoticias/noticias/instituicoes-e-orgaos-publicos-se-unem-no-enfrentamento-eprevencao-do-coronavirus-covid-19/

http://www.ms.gov.br/juntos-contra-0-coronavirus-empresarios-associacoes-e-instituicoes-realizam-doacoes-e-servicos/ 


\section{Fontes dos dados qualitativos por município}

\section{Campo Largo-PR}

https://leismunicipais.com.br/a/pr/c/campo-largo/decreto/2020/11/104/decreto-n-104-2020-institui-0-comite-degestao-de-crise-para-0-covid-19-no-municipio-de-campo-largo-e-da-outras-providencias?q=covid-19

https://leismunicipais.com.br/a/pr/c/campo-largo/decreto/2020/9/81/decreto-n-81-2020-dispoe-sobre-as-medidaspara-enfrentamento-da-emergencia-de-saude-publica-de-importancia-internacional-decorrente-da-infeccao-humanapelo-novo-coronavirus-covid-19?q=covid-19

https://leismunicipais.com.br/a/pr/c/campo-largo/decreto/2020/9/84/decreto-n-84-2020-sumula-declara-situacaode-emergencia-no-ambito-da-saude-publica-no-municipio-de-campo-largo-decorrente-do-coronavirus-covid-19-e-daoutras-providencias?q=covid-19

https://leismunicipais.com.br/a/pr/c/campo-largo/decreto/2020/12/111/decreto-n-111-2020-declara-estado-decalamidade-publica-no-ambito-da-saude-publica-no-municipio-de-campo-largo-decorrente-do-coronavirus-covid-19-e-da-outras-providencias?q=covid-19

https://leismunicipais.com.br/a/pr/c/campo-largo/decreto/2020/12/115/decreto-n-115-2020-dispoe-sobre-adistribuicao-de-alimentos-pereciveis-da-agricultura-familiar-e-nao-pereciveis-da-alimentacao-escolar-aos-alunos-darede-publica-municipal-de-ensino-conforme-especifica?q=covid-19

https://leismunicipais.com.br/a/pr/c/campo-largo/decreto/2020/12/117/decreto-n-117-2020-dispoe-sobrea-prorrogacao-dos-prazos-de-vencimentos-dos-tributos-municipais-que-especifica-diante-da-situacao-deemergencia-em-saude-publica-de-importancia-internacional-pela-disseminacao-do-coronavirus-covid-19-e-da-outrasprovidencias?q=covid -19

https://leismunicipais.com.br/a/pr/c/campo-largo/decreto/2020/12/118/decreto-n-118-2020-regulamenta-a-lei-n-2922de-05-de-marco-de-2018-disciplinando-a-concessao-dos-beneficios-eventuais-na-modalidade-auxilio-calamidadepublica-como-medida-de-enfrentamento-a-pandemia-covid-19?q=covid-19

\section{Carapicuíba - SP}

http://www.carapicuiba.sp.gov.br/uploads/imgfck/Decreto\%20-\%20declarando\%20Estado\%20de\%20Calamidadeconvertido.pdf

http://www.carapicuiba.sp.gov.br/uploads/imgfck/Decreto\%20-\%20Comissão\%20Coronav\%C3\%ADrus.pdf http://www.carapicuiba.sp.gov.br/uploads/imgfck/Decreto\%20-\%20Suspensão\%20Serviços\%20Coronav\%C3\%ADrus\%20 ALTERADO.pdf

http://www.carapicuiba.sp.gov.br/index.php/carapicuiba/noticias/detalle/prefeitura-de-carapicuiba-antecipa-recessoescolar-da-rede-municipal

http://www.carapicuiba.sp.gov.br/index.php/educacao/noticias/detalle/prefeitura-de-carapicuiba-distribui-kit-merendaaos-alunos-da-rede-municipal

https://correiopaulista.com/carapicuiba-constroi-lavatorios-comunitarios-para-pessoas-em-situacao-de-rua/ https://catracalivre.com.br/causando/doacoes/

https://www.visaooeste.com.br/carapicuiba-entrega-segundo-centro-de-enfrentamento-ao-coronavirus/ https://correiopaulista.com/carapicuiba-ganha-hospital-de-campanha/

\section{Caxias do Sul-RS}

https://g1.globo.com/rs/rio-grande-do-sul/noticia/2020/03/21/gramado-e-caxias-do-sul-estabelecem-novas-medidasde-prevencao-ao-coronavirus.ghtml 


\section{Fontes dos dados qualitativos por município}

http://pioneiro.clicrbs.com.br/rs/geral/noticia/2020/03/caxias-do-sul-suspende-as-aulas-na-rede-municipal-deeducacao-12293296.html

https://radiosolaris.com.br/prefeitura-de-caxias-do-sul-decide-suspender-aulas-por-15-dias/

https://caxias.rs.gov.br/noticias/2020/03/coronavirus-prefeitura-cria-gabinete-de-crise-para-acompanhar-os-casos-nacidade

https://caxias.rs.gov.br/noticias/2020/03/prefeitura-anuncia-novas-medidas-para-conter-o-coronavirus

http://pioneiro.clicrbs.com.br/rs/geral/noticia/2020/03/hospital-de-campanha-em-caxias-podera-ser-construido-sehouver-pico-de-casos-de-coronavirus-12294255.html

https://www.jornaldocomercio.com/_conteudo/especiais/coronavirus/2020/04/732942-industria-servicos-e-construca0civil-retomam-atividades-em-caxias-do-sul.html

https://caxias.rs.gov.br/noticias/2020/03/coronavirus-novo-decreto-municipal-suspende-mais-uma-serie-de-atividadesno-municipio

https://caxias.rs.gov.br/noticias/2020/04/prefeitura-de-caxias-decreta-situacao-de-calamidade-publica http://pioneiro.clicrbs.com.br/rs/geral/noticia/2020/04/cestas-basicas-sao-distribuidas-a-estudantes-de-escolasmunicipais-de-caxias-do-sul-12317855.html

https://caxias.rs.gov.br/noticias/2020/04/prefeitura-inicia-distribuicao-de-cestas-basicas-para-familias-de-estudantesda-rede-municipal

https://caxias.rs.gov.br/noticias/2020/02/prefeitura-de-caxias-institui-comissao-para-enfrentamento-do-coronavirus http://pioneiro.clicrbs.com.br/rs/geral/noticia/2020/04/coronavirus-industrias-de-caxias-retornam-as-atividades-a-partirde-segunda-feira-12317888.html

https://caxias.rs.gov.br/noticias/2020/04/coronavirus-prefeitura-fara-hospital-de-campanha-no-pompeia https://radiocaxias.com.br/portal/noticias/prefeitura-de-caxias-cria-gabinete-de-crise-e-governo-do-estado-suspendeatividades-coletivas-112679

\section{Cianorte-PR}

https://g1.globo.com/pr/norte-noroeste/noticia/2020/03/19/coronavirus-idosos-serao-proibidos-de-utilizar-transportepublico-e-comercio-sera-fechado-em-cianorte.ghtml

https://folhadecianorte.com/prefeito-anuncia-segundo-caso-de-coronavirus-em-cianorte-e-adota-novas-medidas/ https://www.cbnmaringa.com.br/noticia/cianorte-reabre-parte-do-comercio-nesta-quarta-feira-1 https://leismunicipais.com.br/a/pr/c/cianorte/decreto/2020/5/42/decreto-n-42-2020?q=covid-19

\section{Coronel Fabriciano-MG}

https://www.otempo.com.br/cidades/com-caso-de-covid-19-coronel-fabriciano-reabre-comercio-com-algumascondicoes-1.2317562

https://www.diariodoaco.com.br/noticia/0076863-com-0-comarcio-fechado-centro-de-ipatinga-ficou-vazio-neste-sabado https://www.fabriciano.mg.gov.br/materia/fabriciano-reabre-comercio-com-restricoes-escolas-e-idosos-sao-mantidosem-isolamento

https://www.fabriciano.mg.gov.br/materia/prefeitura-de-fabriciano-anuncia-medidas-preventivas-e-unidade-exclusivapara-casos-de-coronavirus 


\section{Fontes dos dados qualitativos por município}

https://defatoonline.com.br/prefeitura-de-fabriciano-prorroga-pagamento-do-iptu-e-tributos-municipais/ https://www.fabriciano.mg.gov.br/storage/diarioltem/204513202003205e755589a809e.pdf https://www.fabriciano.mg.gov.br/storage/diarioltem/204513202003205e755589a809e.pdf https://www.fabriciano.mg.gov.br/materia/banco-de-alimentos-de-fabriciano-entrega-cestas-basicas-e-amplia-adistribuicao-de-hortalicas-para-familias-carentes https://www.diariodoaco.com.br/noticia/0077207-pagamento-do-iptu-sera-prorrogado-em-coronel-fabriciano-e-emtimateo

\section{Curitiba-PR}

https://g1.globo.com/pr/parana/educacao/noticia/2020/03/16/prefeitura-determina-suspensao-das-aulas-em-curitiba-apartir-da-proxima-semana-por-conta-do-coronavirus.ghtml

http://www.mppr.mp.br/2020/04/22517,11/Ministerio-Publico-do-Parana-mantem-indicacao-de-respeito-asdeterminacoes-sanitarias-de-isolamento-para-controle-da-pandemia-de-coronavirus.html https://mid.curitiba.pr.gov.br/2020/00296738.pdf https://mid.curitiba.pr.gov.br/2020/00296733.pdf https://mid.curitiba.pr.gov.br/2020/00296733.pdf https://mid.curitiba.pr.gov.br/2020/00296575.pdf https://cbncuritiba.com/curitiba-integra-forca-tarefa-internacional-para-reduzir-crise-economica-com-covid-19/ https://www.gazetadopovo.com.br/parana/o-que-abre-e-fecha-apos-os-decretos-de-estado-de-emergencia-no-parana-eem-curitiba/

https://mid.curitiba.pr.gov.br/2020/00295600.pdf https://mid.curitiba.pr.gov.br/2020/00295780.pdf https://mid.curitiba.pr.gov.br/2020/00295871.pdf https://mid.curitiba.pr.gov.br/2020/00296795.pdf https://noticias.uol.com.br/politica/ultimas-noticias/2020/04/15/prefeito-diz-curitiba-vai-reabrir-comercio-e-relaxarisolamento-na-sexta.htm https://www.tribunapr.com.br/noticias/curitiba-regiao/curitiba-nao-precisa-de-hospital-de-campanha-por-ora-mas-templano-b-no-barigui/ https://www.bemparana.com.br/noticia/prefeitura-faz-forca-tarefa-para-higienizar-75-pontos-proximos-a-hospitais-desp-896\#.XptS-i-z30Q

\section{Divinópolis-MG}

https://www.em.com.br/app/noticia/gerais/2020/04/13/interna_gerais,1138257/coronavirus-prefeitura-de-divinopolisdeclara-calamidade-publica.shtml

https://g1.globo.com/mg/centro-oeste/noticia/2020/03/16/coronavirus-prefeitura-de-divinopolis-assina-decreto-deemergencia.ghtml

https://g1.globo.com/mg/centro-oeste/noticia/2020/03/19/coronavirus-prefeito-restringe-funcionamento-deestabelecimentos-em-divinopolis-por-meio-de-decreto.ghtml 


\section{Fontes dos dados qualitativos por município}

https://g1.globo.com/mg/centro-0este/noticia/2020/04/02/novo-decreto-libera-funcionamento-de-alguns-setores-docomercio-em-divinopolis.ghtml

https://g1.globo.com/mg/centro-oeste/noticia/2020/03/26/alimentos-destinados-a-merenda-escolar-em-divinopolisserao-doados-para-banco-de-alimentos.ghtml

https://g1.globo.com/mg/centro-oeste/noticia/2020/04/14/coronavirus-funcionamento-do-hospital-de-campanha-emdivinopolis-sera-conforme-demanda-da-upa.ghtml

\section{Feira de Santana-BA}

https://www.correio24horas.com.br/noticia/nid/coronavirus-escolas-municipais-de-feira-de-santana-terao-aulassuspensas/

https://www.correi024horas.com.br/noticia/nid/coronavirus-prefeitura-de-feira-de-santana-prorroga-fechamento-docomercio/

https://www.metro1.com.br/noticias/bahia/88860,coronavirus-feira-de-santana-decreta-estado-de-emergencia https://g1.globo.com/ba/bahia/noticia/2020/03/31/prefeitura-de-feira-de-santana-distribuira-cestas-basicas-e-materiaisde-higiene-para-familias-carentes.ghtml

https://www.diariooficial.feiradesantana.ba.gov.br/atos/executivo/13FMTK2032020.pdf

https://www.facebook.com/prefeituradefeiradesantana/posts/1428281980676707:0 https://www.diariooficial.feiradesantana.ba.gov.br/atos/executivo/1C7Y1B2432020.pdf https://www.diariooficial.feiradesantana.ba.gov.br/atos/executivo/1C7Y1B2432020.pdf https://www.diariooficial.feiradesantana.ba.gov.br/atos/executivo/13C7BN2332020.pdf https://www.diariooficial.feiradesantana.ba.gov.br/atos/executivo/1U09001832020.pdf https://www.diariooficial.feiradesantana.ba.gov.br/atos/executivo/ED-1246-EXT-16-03-20.pdf

\section{Ferraz de Vasconcelos-SP}

https://g1.globo.com/sp/mogi-das-cruzes-suzano/noticia/2020/04/16/ferraz-de-vasconcelos-investe-r-5-milhoes-emhospital-de-campanha.ghtml

https://g1.globo.com/sp/mogi-das-cruzes-suzano/noticia/2020/03/16/coronavirus-veja-medidas-adotadas-pelaprefeitura-de-ferraz.ghtml

http://ferrazdevasconcelos.sp.gov.br/web/wp-content/uploads/2020/04/DECRET0-6182-2020-Estado-de-CalamidadePublica-decorrente-da-pandemia-do-Coronavirus.pdf

https://oidiario.com.br/alimentacao-escolar-ferraz/

\section{Florianópolis-SC}

https://leismunicipais.com.br/a/sc/f/florianopolis/decreto/2020/2136/21352/decreto-n-21352-2020-declarasituacao-anormal-caracterizada-como-situacao-de-emergencia-no-municipio-de-florianopolis-em-razao-da-pandemiadecorrente-da-infeccao-humana-pelo-novo-coronavirus-covid-19-0-avanco-das-infeccoes-no-brasil-e-da-outrasprovidencias?q=covid -19

https://leismunicipais.com.br/a/sc/f/florianopolis/decreto/2020/2136/21354/decreto-n-21354-2020-aprimora-asmedidas-de-enfrentamento-ao-covid-19-altera-0-decreto-n-21340-de-2020-suspende-os-efeitos-do-decreto-n-12374de-2013-e-da-outras-providencias? $q=$ covid-19 


\section{Fontes dos dados qualitativos por município}

https://leismunicipais.com.br/a/sc/f/florianopolis/decreto/2020/2137/21361/decreto-n-21361-2020-dispoe-sobre-oatendimento-extraordinario-nas-unidades-educativas-durante-o-periodo-de-enfrentamento-ao-covid-19-e-da-outras-providencias?q=covid-19

https://g1.globo.com/sc/santa-catarina/noticia/2020/04/17/florianopolis-autoriza-reabertura-do-comercio-de-rua-ehoteis-a-partir-da-proxima-semana.ghtml

https://leismunicipais.com.br/a/sc/f/florianopolis/decreto/2020/2137/21365/decreto-n-21365-2020-dispoe-sobre-aprorrogacao-do-vencimento-das-parcelas-do-imposto-sobre-servico-de-qualquer-natureza-iss-fixo-do-ano-2020-emdecorrencia-da-pandemia-relacionada-ao-coronavirus-covid-19?q=covid-19

https://ndmais.com.br/noticias/prefeito-de-florianopolis-defende-fechamento-do-comercio-apos-fala-da-cdl/ https://ndmais.com.br/noticias/coronavirus-instituicoes-pedem-itens-basicos-em-florianopolis-veja-como-ajudar/ (blank)

https://leismunicipais.com.br/a/sc/f/florianopolis/decreto/2020/2137/21368/decreto-n-21368-2020-prorroga-asmedidas-de-enfrentamento-ao-covid-19-e-da-outras-providencias?q=covid-19

https://leismunicipais.com.br/a/sc/f/florianopolis/decreto/2020/2139/21388/decreto-n-21388-2020-estabelece-asregras-de-operacao-do-programa-juro-zero-floripa-durante-a-vigencia-das-acoes-de-enfrentamento-ao-covid-19-alterao-decreto-n-17809-de-2017-e-da-outras-providencias?q=covid-19

https://leismunicipais.com.br/a/sc/f/florianopolis/decreto/2020/2143/21421/decreto-n-21421-2020-prorroga-asmedidas-de-enfrentamento-ao-covid-19-e-da-outras-providencias?q=covid-19

https://g1.globo.com/sc/santa-catarina/noticia/2020/04/12/ultimas-noticias-de-coronavirus-de-12-de-abril-em-sc.ghtml https://g1.globo.com/sc/santa-catarina/noticia/2020/04/16/sc-tem-30-mortes-por-coronavirus-e-926-casosconfirmados.ghtml

https://ndmais.com.br/noticias/microempreendedores-de-florianopolis-tem-suporte-para-retomar-negocios-aposquarentenan/

https://ndmais.com.br/noticias/tecnologia-e-aliada-em-acoes-da-prefeitura-para-o-combate-ao-coronavirus-emflorianopolis/

https://oglobo.globo.com/sociedade/coronavirus-servico/florianopolis-tem-big-brother-contra-covid-19-com-envio-desms-visita-casos-suspeitos-24367110

\section{Fortaleza-CE}

https://g1.globo.com/ce/ceara/noticia/2020/03/23/kits-de-refeicao-para-alunos-da-rede-municipal-de-fortaleza-saodistribuidos-nesta-segunda.ghtml

https://g1.globo.com/ce/ceara/noticia/2020/03/20/kits-de-merenda-escolar-para-alunos-da-rede-publica-de-fortalezacomecam-a-ser-distribuidos-nesta-segunda-diz-prefeitura.ghtml

https://g1.globo.com/ce/ceara/noticia/2020/03/19/decreto-que-determina-fechamento-de-comercio-no-cearaestabelece-multa-de-r-50-em-caso-de-descumprimento.ghtml

https://www.opovo.com.br/coronavirus/2020/04/04/prefeitura-de-fortaleza-garante-524-leitos-para-pacientesinfectados-pelo-novo-coronavirus.html

https://www.opovo.com.br/coronavirus/2020/04/16/confira-as-medidas-de-auxilio-emergencial-ja-anunciadas-pelosgovernos.html 


\section{Fontes dos dados qualitativos por município}

https://g1.globo.com/ce/ceara/noticia/2020/04/01/fortaleza-esta-entre-70-cidades-integrantes-de-forca-tarefa-globalcontra-0-novo-coronavirus.ghtml

https://g1.globo.com/ce/ceara/noticia/2020/04/08/fortaleza-credencia-comercios-para-distribuicao-de-cestas-basicas. ghtml

https://www.opovo.com.br/coronavirus/2020/04/02/kit-de-alimentacao-serao-distribuidos-para-integrantes-do-cadastrodo-bolsa-familia-em-fortaleza--garante-prefeito.html

https://g1.globo.com/ce/ceara/noticia/2020/04/06/prefeitura-de-fortaleza-suspende-pagamento-de-imposto-paraempresas-veja-quem-se-beneficia.ghtml

https://www.opovo.com.br/coronavirus/2020/04/18/coronavirus-fortaleza-hospital-de-campanha-no-pv-hoje-sabadovideo-fotos.html

https://diariodonordeste.verdesmares.com.br/editorias/politica/online/camara-municipal-de-fortaleza-destina-r-7-milhoespara-tratamento-de-pacientes-com-coronavirus-1.2227074

https://diariodonordeste.verdesmares.com.br/editorias/metro/online/campanha-supera-fortaleza-ajuda-trabalhadoresinformais-afetados-pela-quarentena-1.2225461

https://www.opovo.com.br/coronavirus/2020/04/04/prefeitura-de-fortaleza-lanca-programa-para-producao-de-2-5milhoes-de-mascaras-de-tecido.html

\section{Foz do Iguaçu-PR}

https://g1.globo.com/pr/oeste-sudoeste/noticia/2020/03/15/coronavirus-prefeitura-de-foz-do-iguacu-suspende-aulas-darede-municipal-a-partir-de-terca-feira-17.ghtml

https://leismunicipais.com.br/a/pr/f/foz-do-iguacu/decreto/2020/2803/28030/decreto-n-28030-2020-altera-0-decreton-28021-de-6-de-abril-de-2020-que-regulamenta-a-lei-n-4829-de-20-de-dezembro-de-2019-que-institui-o-programa-de-microfinancas-foz-juro-zero?q=covid-19

https://leismunicipais.com.br/a/pr/f/foz-do-iguacu/decreto/2020/2803/28026/decreto-n-28026-2020-define-atividadesque-poderao-retomar-de-forma-gradual-e-monitorada-com-assuncao-reciproca-de-responsabilidade-sanitariano-municipio-de-foz-do-iguacu-no-enfrentamento-da-emergencia-em-saude-publica-de-importancia-internacionaldecorrente-da-pandemia-do-novo-coronavirus-covid-19?q=covid-19

https://www.radioculturafoz.com.br/2020/03/22/cestas-basicas-serao-entregues-primeiro-para-familias-das-criancasda-rede-municipal-de-ensino/

https://leismunicipais.com.br/a/pr/f/foz-do-iguacu/decreto/2020/2803/28025/decreto-n-28025-2020-constitui-comitede-crise-para-enfrentamento-do-covid-19-no-ambito-do-municipio-de-foz-do-iguacu?q=covid-19

https://leismunicipais.com.br/a/pr/f/foz-do-iguacu/decreto/2020/2798/27972/decreto-n-27972-2020-adota-medidasadicionais-de-controle-prevencao-e-fiscalizacao-para-enfrentamento-da-emergencia-em-saude-publica-de-importanciainternacional-decorrente-do-novo-coronavirus-covid-19-em-complemento-ao-decreto-n-29963-de-15-de-marco-de2020?q=covid -19

https://www.clickfozdoiguacu.com.br/foz-do-iguacu-vai-disponibilizar-quartos-de-hoteis-para-quarentena-do-novocoronavirus/

https://leismunicipais.com.br/a/pr/f/foz-do-iguacu/decreto/2020/2800/28000/decreto-n-28000-2020-declara-estadode-calamidade-publica-no-municipio-de-foz-do-iguacu-em-decorrencia-da-pandemia-do-novo-coronavirus?q=covid-19 


\section{Fontes dos dados qualitativos por município}

https://leismunicipais.com.br/a/pr/f/foz-do-iguacu/decreto/2020/2800/27994/decreto-n-27994-2020-consolida-asmedidas-estabelecidas-no-municipio-de-foz-do-iguacu-e-declara-situacao-de-emergencia-ao-controle-e-prevencaopara-o-enfrentamento-da-emergencia-em-saude-publica-de-importancia-internacional-decorrente-da-pandemia-donovo-coronavirus-covid-19?q=covid-19

https://leismunicipais.com.br/a/pr/f/foz-do-iguacu/decreto/2020/2799/27981/decreto-n-27981-2020-complementa-asdeterminacoes-relativas-a-situacao-de-emergencia-constantes-no-decreto-n-27980-de-19-de-marco-de-2020-que-declara-situacao-de-emergencia-no-municipio-de-foz-do-iguacu-e-define-outras-medidas-de-enfrentamento-da-pandemiadecorrente-do-coronavirus-e-todas-as-demais-medidas-ja-estabelecidas? $\mathrm{q}=$ covid-19

https://leismunicipais.com.br/a/pr/f/foz-do-iguacu/decreto/2020/2798/27980/decreto-n-27980-2020-declara-situacaode-emergencia-no-municipio-de-foz-do-iguacu-e-define-outras-medidas-de-enfrentamento-da-pandemia-decorrente-docoronavirus?q=covid -19

https://g1.globo.com/pr/oeste-sudoeste/noticia/2020/04/16/projeto-preve-fazer-testes-da-covid-19-em-28-milmoradores-e-mapear-doenca-em-foz-do-iguacu.ghtml

https://foz.portaldacidade.com/noticias/saude/fundo-de-us-3-milhoes-da-itaipu-para-enfrentar-0-coronavirus-ja-esta-emvigor-5739

https://www.radioculturafoz.com.br/2020/04/15/prefeitura-recebe-doacao-de-alcool-glicerinado-80-da-unila/

\section{Goiânia-G0}

https://g1.globo.com/go/goias/noticia/2020/04/17/prefeitura-de-goiania-comeca-distribuir-cestas-basicas-a-alunos-queestao-sem-aulas-e-merenda-por-causa-da-pandemia.ghtml

https://g1.globo.com/go/goias/noticia/2020/03/15/saude-estadual-suspende-aulas-por-15-dias-em-goias.ghtml https://g1.globo.com/go/goias/noticia/2020/03/19/goias-fecha-comercio-shoppings-feiras-e-academias-apos-decretopara-conter-coronavirus.ghtml

https://g1.globo.com/go/goias/noticia/2020/03/23/prefeitura-de-goiania-decreta-calamidade-publica-em-razao-docoronavirus.ghtml

https://www.emaisgoias.com.br/alunos-da-rede-municipal-de-goiania-devem-ganhar-kits-de-alimentacao-nos-proximosdias/

https://g1.globo.com/go/goias/noticia/2020/04/02/jovem-de-27-anos-que-morreu-a-caminho-do-hospital-de-campanhanao-tinha-coronavirus-diz-ses.ghtml

\section{Guarulhos-SP}

https://www.guarulhos.sp.gov.br/article/centro-de-combate-ao-coronavirus-da-alta-ao-primeiro-paciente-curado-dacovid-19

https://www.guarulhos.sp.gov.br/article/decreto-institui-novas-regras-e-reabertura-gradativa-partir-de-6-de-maio https://www.guarulhos.sp.gov.br/article/prefeitura-anuncia-novas-medidas-para-contencao-do-coronavirus-em-guarulhos https://www.guarulhos.sp.gov.br/article/prefeitura-anuncia-novas-medidas-para-contencao-do-coronavirus-em-guarulhos https://www.guarulhos.sp.gov.br/article/guarulhos-decreta-emergencia-em-razao-do-coronavirus-e-suspende-aulaspartir-do-dia-23

https://www.guarulhos.sp.gov.br/article/guarulhos-decreta-estado-de-calamidade-publica

https://agenciabrasil.ebc.com.br/saude/noticia/2020-04/prefeitura-de-guarulhos-promove-2a-edicao-do-drive-thrusolidario 
RAP | 0 surto da COVID-19 e as respostas da administração municipal: munificência de recursos, vulnerabilidade social e eficácia de ações públicas

\section{Fontes dos dados qualitativos por município}

\section{Ipatinga-MG}

https://leismunicipais.com.br/a/mg/i/ipatinga/decreto/2020/928/9280/decreto-n-9280-2020-determina-a-suspensaodas-atividades-que-menciona-e-da-outras-providencias?q=covid-19

https://leismunicipais.com.br/a/mg/i/ipatinga/decreto/2020/928/9277/decreto-n-9277-2020-determina-a-suspensaodas-atividades-de-estudios-academias-de-ginastica-e-estabelecimentos-congeneres-e-outros-que-menciona-e-daoutras-providencias?q=covid-19

https://leismunicipais.com.br/a/mg/i/ipatinga/decreto/2020/928/9273/decreto-n-9273-2020-decreta-situacao-deemergencia-em-saude-publica-no-municipio-de-ipatinga-estabelece-medidas-de-prevencao-e-enfrentamento-em-faceda-possibilidade-de-surto-de-doenca-infecciosa-viral-respiratoria-covid-19-e-da-outras-providencias?q=covid-19 https://portalnegociosja.com.br/ipatinga-prorroga-prazo-para-pagamento-do-iptu/ https://plox.com.br/noticia/16/04/2020/ipatinga-tem-estado-de-calamidade-publica-reconhecido-pela-assembleia-deminas

https://defatoonline.com.br/ipatinga-vai-distribuir-cestas-basicas-para-familias-de-alunos-carentes/

https://g1.globo.com/mg/vales-mg/noticia/2020/03/17/coronavirus-prefeitura-de-ipatinga-manda-suspender-academiascinema-e-escola-de-idiomas.ghtml

https://www.diariodoaco.com.br/noticia/0077365-comarcio-de-ipatinga-volta-a-funcionar-com-medidas-preventivas https://g1.globo.com/mg/vales-mg/noticia/2020/04/15/prefeitura-de-ipatinga-comeca-a-distribuir-kits-de-alimentacaopara-alunos-da-rede-municipal.ghtml

https://www.ipatinga.mg.gov.br/detalhe-da-materia/info/alivio-para-8-mil-familias-kits-de-alimentacao-sao-entreguesem-ipatinga/96348

https://g1.globo.com/mg/vales-mg/noticia/2020/04/06/hospital-de-campanha-comeca-a-ser-implantado-em-ipatingapara-receber-pacientes-com-encaminhamento-entenda.ghtml

https://www.ipatinga.mg.gov.br/detalhe-da-materia/info/combate-ao-coronavirus-ipatinga-realiza-1a-reuniao-do-comitede-gestao-de-crise/96244

\section{Jaboatão dos Guararapes-PE}

https://folhape.com.br/politica/politica/coronavirus/2020/03/14/NWS,133510,7,1682,POLITICA,2193-PREFEITOJABOATAO-DOS-GUARARAPES-DIVULGA-ACOES-ENFRENTAMENTO-NOVO-CORONAVIRUS.aspx

https://jaboatao.pe.gov.br/jaboataoprev-adota-medidas-de-prevencao-ao-coronavirus/

https://diariooficial.jaboatao.pe.gov.br/30-de-marco-de-2020-xxx-no-062-jaboatao-dos-guararapes-edicaoextraordinaria/

https://diariooficial.jaboatao.pe.gov.br/23-de-marco-de-2020-xxx-no-056-jaboatao-dos-guararapes-edicaoextraordinaria/

https://www.diariodepernambuco.com.br/noticia/vidaurbana/2020/04/jaboatao-entrega-730-toneladas-de-alimentospara-estudantes-da-rede-mu.html

https://www.diariodepernambuco.com.br/noticia/vidaurbana/2020/04/distribuicao-de-cestas-basicas-para-estudantesda-rede-publica-de-paul.html

https://jc.ne10.uol.com.br/pernambuco/2020/03/5602440-aulas-da-rede-municipal-de-jaboatao-estao-suspensas-apartir-de-quarta-por-conta-do-coronavirus.html 


\section{Fontes dos dados qualitativos por município}

https://g1.globo.com/pe/pernambuco/noticia/2020/04/04/unidade-das-lojas-americanas-em-jaboatao-e-interditada-peloprocon-e-gerente-e-detido.ghtml

https://www.folhape.com.br/noticias/noticias/coronavirus/2020/04/15/NWS,137314,70,1668,NOTICIAS,2190-RUASJABOATAO-TEM-AGLOMERACOES-MEIO-PANDEMIA-COVID.aspx

\section{Joinville-SC}

https://leismunicipais.com.br/a/sc/j/joinville/resolucao/2020/8/72/resolucao-n-72-2020-cria-comissao-especial-paraexaminar-acompanhar-e-opinar-sobre-a-emergencia-de-saude-publica-de-importancia-internacional-relacionada-aocoronavirus-covid-19?q=covid -19

https://gauchazh.clicrbs.com.br/economia/noticia/2020/04/cidades-catarinenses-reabrem-comercio-florianopolismantem-quarentena-ck901t32m00d301p5exoyujxa.html

https://www.nsctotal.com.br/colunistas/saavedra/coronavirus-em-joinville-as-expectativas-na-prefeitura-para-osproximos-dias

https://ndmais.com.br/noticias/coronavirus-joinville-decreta-situacao-de-emergencia/

https://www.nsctotal.com.br/noticias/coronavirus-em-joinville-servicos-nao-essenciais-nao-podem-ter-trabalho-internodiz-pm

https://ndmais.com.br/noticias/coronavirus-apos-decreto-veja-o-que-abre-e-fecha-em-joinville/

https://ndmais.com.br/noticias/coronavirus-decreto-estabelece-medidas-para-minimizar-impacto-economico-em-joinville/ https://g1.globo.com/sc/santa-catarina/noticia/2020/03/31/cidades-de-sc-distribuem-cestas-basicas-para-familias-debaixa-renda-veja-como-pedir.ghtml

\section{Juiz de Fora-MG}

https://www.pjf.mg.gov.br/e_atos/e_atos_vis.php?id=75321

https://www.pjf.mg.gov.br/e_atos/e_atos_vis.php?id=74964

https://www.pjf.mg.gov.br/e_atos/e_atos_vis.php?id=75017

https://www.acessa.com/cidade/arquivo/noticias/2020/03/25-pjf-governo-estadual-criam-forca-tarefa-para-arrecadacaovoluntaria-doacoes/

https://www.pjf.mg.gov.br/e_atos/e_atos_vis.php?id=75128

https://www.em.com.br/app/noticia/gerais/2020/04/16/interna_gerais,1139263/prefeitura-e-ufff-fazem-convenio-paracombate-ao-coronavirus.shtml

https://www.pjf.mg.gov.br/e_atos/e_atos_vis.php?id=75188

https://g1.globo.com/mg/zona-da-mata/noticia/2020/03/16/por-causa-do-coronavirus-prefeito-de-juiz-de-forasuspende-aulas-e-eventos-com-aglomeracao.ghtml

https://g1.globo.com/mg/zona-da-mata/noticia/2020/03/20/comercio-de-juiz-de-fora-e-alvo-de-fiscalizacao-por-contado-coronavirus.ghtml

https://www.correiobraziliense.com.br/app/noticia/brasil/2020/04/16/interna-brasil,845250/prefeitura-e-ufif-fazemconvenio-para-combate-ao-coronavirus.shtml

https://g1.globo.com/mg/zona-da-mata/noticia/2020/04/15/prefeitura-formaliza-comite-municipal-de-enfrentamento-eprevenca0-a-covid-19-em-juiz-de-fora.ghtml 


\section{Fontes dos dados qualitativos por município}

https://www.em.com.br/app/noticia/gerais/2020/04/16/interna_gerais,1139263/prefeitura-e-ufff-fazem-convenio-paracombate-ao-coronavirus.shtml

https://www.acessa.com/cidade/arquivo/noticias/2020/03/25-pjf-governo-estadual-criam-forca-tarefa-para-arrecadacaovoluntaria-doacoes/

\section{Londrina-PR}

https://leismunicipais.com.br/a/pr///londrina/decreto/2020/35/346/decreto-n-346-2020-decreta-situacao-deemergencia-no-municipio-de-Iondrina-como-medida-de-enfrentamento-da-pandemia-decorrente-do-novo-coronavirus-covid-19-e-da-outras-providencias?q=covid-19

https://www.bonde.com.br/bondenews/londrina/confira-0-que-abre-e-fecha-em-londrina-durante-a-quarentena-514094. html

https://www.folhadelondrina.com.br/cidades/educacao-de-Iondrina-estuda-plano-para-quarentena-2985143e.html https://www.bonde.com.br/bondenews/londrina/municipio-ofertara-merenda-escolar-durante-suspensao-dasaulas-514075.html https://g1.globo.com/pr/norte-noroeste/noticia/2020/03/31/prefeitura-de-londrina-anuncia-pacote-economico-contrarecessao-provocada-pelo-coronavirus.ghtml

https://www.folhadelondrina.com.br/economia/comercio-ficara-fechado-em-londrina-pelo-menos-ate-dia-20-2986210e. html

https://g1.globo.com/pr/parana/educacao/noticia/2020/03/16/prefeitura-determina-suspensao-das-aulas-em-curitiba-apartir-da-proxima-semana-por-conta-do-coronavirus.ghtml

\section{Maceió-AL}

https://g1.globo.com/al/alagoas/noticia/2020/03/15/veja-as-medidas-de-prevencao-ao-coronavirus-adotadas-emalagoas.ghtml

https://g1.globo.com/al/alagoas/noticia/2020/03/17/escolas-estaduais-de-alagoas-e-municipais-de-maceio-suspendemaulas-por-15-dias-mas-mantem-merenda-aos-alunos.ghtml

https://g1.globo.com/al/alagoas/noticia/2020/03/17/as-aulas-serao-suspensas-diz-prefeito-de-maceio-sobre-prevencaoao-novo-coronavirus.ghtml

https://g1.globo.com/al/alagoas/noticia/2020/03/20/alagoas-fecha-igrejas-shoppings-bares-e-outros-estabelecimentosisolamento-total-diz-governador.ghtml

https://g1.globo.com/al/alagoas/post/2020/04/08/decreto-da-desconto-de-ate-30percent-no-valor-do-iptu-em-maceio. ghtml

https://g1.globo.com/al/alagoas/noticia/2020/04/01/kits-de-merenda-escolar-para-alunos-da-rede-publica-de-maceiocomecam-a-ser-distribuidos-na-quinta.ghtml

https://gazetaweb.globo.com/portal/noticia/2020/03/coronavirus-prefeitura-de-maceio-adota-medidas-para-atividadescomerciais-_100313.php

https://gazetaweb.globo.com/portal/noticia/2020/03/coronavirus-prefeitura-de-maceio-adota-medidas-para-atividadescomerciais-_100313.php

https://g1.globo.com/al/alagoas/noticia/2020/03/25/prefeitura-de-maceio-adia-em-90-dias-vencimento-do-iptu-porcausa-do-surto-do-coronavirus.ghtml 


\section{Fontes dos dados qualitativos por município}

\section{Manaus-AM}

https://leismunicipais.com.br/a/am/m/manaus/lei-ordinaria/2020/260/2595/lei-ordinaria-n-2595-2020-institui-oprograma-nossa-merenda-no-ambito-do-municipio-de-manaus-como-medida-emergencial-de-enfrentamento-apandemia-da-covid-19-e-da-outras-providencias?q=covid-19

https://leismunicipais.com.br/a/am/m/manaus/lei-ordinaria/2020/260/2596/lei-ordinaria-n-2596-2020-dispoe-sobre-aconcessao-de-bolsa-auxilio-emergencial-em-razao-da-pandemia-causada-pelo-novo-coronavirus-covid-19-e-da-outrasprovidencias? $\mathrm{q}=$ covid -19

https://leismunicipais.com.br/a/am/m/manaus/decreto/2020/478/4780/decreto-n-4780-2020-declara-situacao-anormalcaracterizada-como-emergencial-no-municipio-de-manaus-e-da-outras-providencias?q=covid-19

https://leismunicipais.com.br/a/am/m/manaus/decreto/2020/479/4787/decreto-n-4787-2020-declara-estado-decalamidade-publica-no-municipio-de-manaus-para-enfrentamento-da-pandemia-do-covid-19-e-da-outras-providencias?q=covid -19

https://g1.globo.com/jornal-nacional/noticia/2020/04/14/hospital-de-campanha-de-manaus-recebe-os-cinco-primeirospacientes-com-coronavirus.ghtml

https://leismunicipais.com.br/a/am/m/manaus/decreto/2020/480/4791/decreto-n-4791-2020-dispoe-sobre-a-proibicaode-suspensao-dos-servicos-publicos-de-abastecimento-de-agua-e-de-esgotamento-sanitario-da-cidade-de-manaus-emface-da-pandemia-de-covid-19-pelo-prazo-de-60-sessenta-dias-e-da-outras-providencias?q=covid-19

https://leismunicipais.com.br/a/am/m/manaus/decreto/2020/480/4796/decreto-n-4796-2020-dispoe-sobre-0-bloqueiotemporario-da-venda-e-utilizacao-de-cartoes-de-meia-passagem-estudantil-e-da-concessao-de-gratuidade-a-idosos-notransporte-coletivo-de-passageiros-no-municipio-de-manaus-e-da-outras-providencias?q=covid-19

https://leismunicipais.com.br/a/am/m/manaus/decreto/2020/481/4803/decreto-n-4803-2020-regulamenta-a-lei-n2596-de-03-de-abril-de-2020-que-dispoe-sobre-a-concessao-da-bolsa-auxilio-emergencial-em-razao-da-pandemia-causada-pelo-novo-coronavirus-covid-19-e-da-outras-providencias? $q=$ covid-19

https://todahora.com/articulos/cmm-aprova-medidas-propostas-pela-prefeitura-de-manaus-para-enfrentamento-a0covid-19

\section{Maringá-PR}

https://g1.globo.com/pr/norte-noroeste/noticia/2020/03/18/coronavirus-prefeitura-decreta-situacao-de-emergencia-edetermina-fechamento-de-comercio.ghtml

https://cbnmaringa.com.br/noticia/maringa-declara-estado-de-calamidade-publica

http://www.mppr.mp.br/2020/04/22505,10/Isolamento-e-a-unica-forma-de-prevenir-contagio-alerta-gabinete-integrado. html

http://www.mppr.mp.br/2020/04/22517,11/Ministerio-Publico-do-Parana-mantem-indicacao-de-respeito-asdeterminacoes-sanitarias-de-isolamento-para-controle-da-pandemia-de-coronavirus.html https://g1.globo.com/pr/norte-noroeste/noticia/2020/04/14/prefeitura-de-maringa-oferece-auxilio-alimentacao-parafamilias-em-vulnerabilidade-social.ghtml

https://g1.globo.com/pr/norte-noroeste/noticia/2020/03/25/prefeitura-de-maringa-prorroga-pagamento-de-impostosmunicipais-para-empresas-e-microempreendedores.ghtml https://cbnmaringa.com.br/noticia/empresarios-de-maringa-se-unem-e-compram-10-respiradores-para-0-hu-de-maringa 


\section{Fontes dos dados qualitativos por município}

\section{Mauá-SP}

http://www.maua.sp.gov.br/Not.aspx?NoticialD=5064

http://www.negociosemmovimento.com.br/destaque-home/covid-19-prefeitura-de-maua-firma-convenio-com-hospitalvital-e-medical-health/

https://www.facebook.com/prefeitura.maua/?_tn__=\%2Cd\%2CP-R\&eid=ARAllj06mF3RIN9VcmH8oarX914AG_ edy5YCutofU_OYK7WJztH49UtYK5_RETUzB7EoMZcG87eSk3dJ

https://abcreporter.com.br/2020/04/16/maua-endurece-medidas-para-isolamento-social-no-combate-ao-coronavirus/ https://g1.globo.com/sp/sao-paulo/noticia/2020/04/15/coronavirus-abc-amplia-funcionamento-de-postos-decombustiveis-e-autoriza-bancas-de-jornais-na-quarentena.ghtml

http://www.maua.sp.gov.br/Not.aspx?noticialD=5066

\section{Natal-RN}

http://portal.natal.rn.gov.br/_anexos/publicacao/dom/dom_20200409_extra_4edd495866e1d12651ca65ab816aa827.pdf http://portal.natal.rn.gov.br/_anexos/publicacao/dom/dom_20200422_c193d2fb15c252b24b09dc88465e0b3e.pdf http://portal.natal.rn.gov.br/_anexos/publicacao/dom/dom_20200403_extra_e9dc672dea6dca79740672aeb5ae5a61.pdf http://portal.natal.rn.gov.br/_anexos/publicacao/dom/dom_20200403_75c815f392c8ee3c548a36229221a4fe.pdf http://portal.natal.rn.gov.br/_anexos/publicacao/dom/dom_20200402_21d968de1b5b6f3d16b93137416790e6.pdf http://portal.natal.rn.gov.br/_anexos/publicacao/dom/dom_20200401_6b3e14163bc79cb01f054e158c1bb6bc.pdf http://portal.natal.rn.gov.br/_anexos/publicacao/dom/dom_20200324_d0603bd4388d5b11fe4a5cca2c383ea2.pdf http://portal.natal.rn.gov.br/_anexos/publicacao/dom/dom_20200321_especial_4749ad6c52cfe40b55a43611c6ab54 ec.pdf

http://portal.natal.rn.gov.br/_anexos/publicacao/dom/dom_20200318_4c3d7ab24f98c1070634eec7158d5cdf.pdf https://g1.globo.com/mg/zona-da-mata/noticia/2020/03/30/prefeitura-distribui-cestas-basicas-para-familias-de-alunosda-rede-municipal-em-vicosa.ghtml

http://www.tribunadonorte.com.br/noticia/hospital-de-campanha-da-prefeitura-do-natal-abrira-no-dia-13/476878 https://g1.globo.com/rn/rio-grande-do-norte/noticia/2020/03/27/coronavirus-prefeitura-de-natal-recua-e-autorizafuncionamento-de-feiras-livres.ghtml

\section{Niterói-RJ}

https://leismunicipais.com.br/a/rj/n/niteroi/lei-ordinaria/2020/348/3477/lei-ordinaria-n-3477-2020-dispoe-sobre-0auxilio-financeiro-temporario-aos-microempreendedores-individuais-em-virtude-dos-impactos-sociais-e-economicos-dapandemia-de-covid-19?q=covid-19

https://leismunicipais.com.br/a/rj/n/niteroi/lei-ordinaria/2020/348/3479/lei-ordinaria-n-3479-2020-dispoe-sobre-aproibicao-de-corte-no-servico-de-fornecimento-de-agua-no-municipio-de-niteroi-em-virtude-da-pandemia-covid-19coronavirus?q=covid -19

https://leismunicipais.com.br/a/rj/n/niteroi/lei-ordinaria/2020/348/3480/lei-ordinaria-n-3480-2020-dispoe-sobre-acriacao-de-renda-basica-temporaria-para-cidadaos-do-municipio-de-niteroi-inscritos-no-cadunico?q=covid-19 https://leismunicipais.com.br/a/rj/n/niteroi/lei-ordinaria/2020/349/3486/lei-ordinaria-n-3486-2020-dispoe-sobre-aconcessao-de-auxilio-emergencial-aos-permissionarios-do-servico-de-taxi-e-seus-auxiliares-bem-como-aos-prestadoresde-servico-de-transporte-escolar-em-virtude-dos-impactos-sociais-e-economicos-da-pandemia-de-covid-19?q=covid-19 


\section{Fontes dos dados qualitativos por município}

https://leismunicipais.com.br/a/rj/n/niteroi/decreto/2020/1351/13505/decreto-n-13505-2020-cria-gabinete-de-crisepara-centralizar-a-tomada-de-decisoes-integrar-e-alinhar-as-iniciativas-do-municipio-na-prevencao-e-assistencia-apopulacao-em-relacao-a-disseminacao-do-virus-covid-19-no-municipio-de-niteroi-e-da-outras-providencias?q=covid-19 https://leismunicipais.com.br/a/rj/n/niteroi/decreto/2020/1351/13506/decreto-n-13506-2020-dispoe-sobre-adeclaracao-de-emergencia-de-saude-publica-decorrente-da-pandemia-do-coronavirus-sobre-a-suspensao-de-aulasna-rede-publica-municipal-de-niteroi-de-16-a-31-de-marco-sobre-as-medidas-de-enfrentamento-e-da-outrasprovidencias?q=covid -19

https://leismunicipais.com.br/a/rj/n/niteroi/decreto/2020/1352/13513/decreto-n-13513-2020-dispoe-sobre-0fechamento-de-bares-restaurantes-shoppings-centers-centros-comerciais-clubes-e-quiosques-de-alimentacao-bem-como-sobre-a-proibicao-de-permanencia-em-praias-e-pracas-e-fechamento-de-acesso-as-praias-da-regiao-oceanicacomo-forma-de-evitar-a-aglomeracao-de-pessoas-e-evitar-o-crescimento-dos-casos-de-cornonavirus-em-niteroi-e-daoutras-providencias?q=covid-19

\section{Nova Lima-MG}

https://www.em.com.br/app/noticia/gerais/2020/04/07/interna_gerais,1136518/alunos-da-rede-municipal-de-novalima-recebem-kits-de-merenda-escolar.shtml

http://www.novalima.mg.gov.br/uploads/legislacoes/1584570807CAxLtl.pdf

https://www.em.com.br/app/noticia/gerais/2020/03/17/interna_gerais, 1129598/coronavirus-nova-lima-declara-situacaoemergencia-apos-1-caso-doenca.shtml

https://tvbanqueta.com.br/2020/03/25/prefeitura-de-nova-lima-viabiliza-solucao-para-pulverizacao-da-cidade/ http://www.novalima.mg.gov.br/uploads/legislacoes/1584570807CAxLtl.pdf http://www.novalima.mg.gov.br/noticias/comunicado-oficial http://www.novalima.mg.gov.br/uploads/legislacoes/1584396913260mPl.pdf https://g1.globo.com/mg/minas-gerais/noticia/2020/03/19/coronavirus-cidades-da-regiao-metropolitana-de-belohorizonte-tambem-fecham-as-portas-do-comercio.ghtml

https://g1.globo.com/mg/minas-gerais/noticia/2020/03/24/por-causa-do-coronavirus-prefeitura-de-nova-lima-estendedata-para-pagamento-do-iptu.ghtml

http://www.novalima.mg.gov.br/noticias/adiamento-do-pagamento-de-taxas-e-impostos

\section{Patrocínio-MG}

https://g1.globo.com/mg/triangulo-mineiro/noticia/2020/03/17/patrocinio-decreta-situacao-de-emergencia-em-saudepublica-e-adota-medidas-de-prevencao-ao-coronavirus.ghtml

https://g1.globo.com/mg/triangulo-mineiro/noticia/2020/03/16/patrocinio-define-acoes-de-prevencao-a-covid-19-aposconfirmacao-do-unico-caso-de-coronavirus-no-triangulo-e-alto-paranaiba.ghtml

https://patrocinioonline.com.br/noticia/prefeito-publica-decreto-suspendendo-aulas-alvaras-de-locais-de-aglomeracao-efenacafe-confira-36032.html

https://g1.globo.com/mg/triangulo-mineiro/noticia/2020/03/28/coronavirus-prefeitura-de-patrocinio-publica-novodecreto-com-restricoes-temporarias-ao-comercio.ghtml

https://g1.globo.com/mg/triangulo-mineiro/noticia/2020/04/10/coronavirus-patrocinio-autoriza-reabertura-do-comercioapos-a-pascoa.ghtml 


\section{Fontes dos dados qualitativos por município}

https://g1.globo.com/mg/triangulo-mineiro/noticia/2020/03/24/patrocinio-determina-novas-restricoes-para-variossetores-em-prevencao-ao-coronavirus.ghtml

\section{Pinhais-PR}

https://leismunicipais.com.br/a/pr/p/pinhais/decreto/2020/32/316/decreto-n-316-2020-estabelece-medidastemporarias-de-prevencao-ao-contagio-pelo-novo-coronavirus-covid-19-considerando-a-classificacao-de-pandemia-pelaorganizacao-mundial-de-saude-oms?q=covid-19

https://leismunicipais.com.br/a/pr/p/pinhais/decreto/2020/32/313/decreto-n-313-2020-institui-o-comite-municipalespecial-de-controle-de-infeccao-do-covid-19-comeci-covid-com-0-objetivo-de-propor-as-estrategias-e-procedimentostecnicos-na-esfera-da-saude-municipal-para-o-enfrentamento-da-situacao-epidemiologica-atual-e-da-outrasprovidencias? $\mathrm{q}=$ covid -19

https://leismunicipais.com.br/a/pr/p/pinhais/decreto/2020/31/303/decreto-n-303-2020-decreto303-20_estabelecemedidas-temporarias-de-prevencao-ao-contagio-pelo-novo-coronavirus-covid-19?q=covid-19

https://leismunicipais.com.br/a/pr/p/pinhais/decreto/2020/29/282/decreto-n-282-2020-decreto282-20_estabelecemedidas-temporarias-de-prevencao-ao-contagio-pelo-novo-coronavirus-covid-19?q=covid-19

https://leismunicipais.com.br/a/pr/p/pinhais/decreto/2020/25/250/decreto-n-250-2020-estabelece-medidastemporarias-de-prevencao-ao-contagio-pelo-novo-coronavirus-covid-19-considerando-a-classificacao-de-pandemia-pelaorganizacao-mundial-de-saude-oms?q=covid-19

https://coronavirus.pinhais.pr.gov.br

\section{Porto Alegre-RS}

https://leismunicipais.com.br/a/rs/p/porto-alegre/decreto/2020/2054/20531/decreto-n-20531-2020-proibe-0funcionamento-de-todos-os-estabelecimentos-comerciais-de-servicos-e-industriais-bem-como-as-atividades-deconstrucao-civil-exceto-os-estabelecimentos-que-menciona-para-enfrentamento-da-emergencia-de-saude-publica-deimportancia-internacional-decorrente-do-novo-coronavirus-covid-19-no-municipio-de-porto-alegre-e-revoga-os-decretosn-20516-de-20-de-marco-de-2020-n-20521-de-20-de-marco-de-2020-e-os-arts-1-e-2-do-decreto-n-20525-de-22de-marco-de-2020?q=covid-19

https://leismunicipais.com.br/a/rs/p/porto-alegre/decreto/2020/2054/20534/decreto-n-20534-2020-decreta-0-estadode-calamidade-publica-e-consolida-as-medidas-para-enfrentamento-da-emergencia-de-saude-publica-de-importanciainternacional-decorrente-do-novo-coronavirus-covid-19-no-municipio-de-porto-alegre?q=covid-19

https://leismunicipais.com.br/a/rs/p/porto-alegre/decreto/2020/2055/20542/decreto-n-20542-2020-dispoe-sobremedidas-para-reduzir-0-impacto-social-e-economico-do-estado-de-calamidade-provocado-pela-emergencia-de-saudepublica-de-importancia-internacional-decorrente-do-novo-coronavirus-covid-19-e-altera-o-caput-do-art-9-do-decreto-n20325-de-6-de-agosto-de-2019?q=covid-19

https://leismunicipais.com.br/a/rs/p/porto-alegre/decreto/2020/2050/20499/decreto-n-20499-2020-dispoe-sobremedidas-a-serem-adotadas-para-0-enfrentamento-da-emergencia-de-saude-publica-decorrente-do-novo-coronaviruscovid-19-no-municipio-de-porto-alegre?q=covid-19

https://leismunicipais.com.br/a/rs/p/porto-alegre/decreto/2020/2051/20506/decreto-n-20506-2020-estabelecemedidas-para-os-estabelecimentos-shoppings-centers-e-centros-comerciais-para-enfrentamento-da-emergenciade-saude-publica-de-importancia-internacional-decorrente-do-novo-coronavirus-covid-19-no-municipio-de-portoalegre?q=covid -19 


\section{Fontes dos dados qualitativos por município}

https://leismunicipais.com.br/a/rs/p/porto-alegre/decreto/2020/2051/20501/decreto-n-20501-2020-institui-0-comitetemporario-de-enfrentamento-ao-coronavirus-ctecov-do-municipio-de-porto-alegre-como-mecanismo-municipalda-gestao-coordenada-em-resposta-a-emergencia-na-saude-publica?q=covid-19

https://www.jornaldocomercio.com/_conteudo/especiais/coronavirus/2020/04/733000-recolhimento-de-icms-e-iss-eadiado-por-90-dias-para-empresas-do-simples.html

https://www.jornaldocomercio.com/_conteudo/especiais/coronavirus/2020/04/733443-prefeitura-disponibilizaparcelamento-do-iptu-em-ate-60-vezes.html

https://leismunicipais.com.br/a/rs/p/porto-alegre/decreto/2020/2053/20521/decreto-n-20521-2020-determinao-fechamento-dos-estabelecimentos-comerciais-construcoes-civis-industriais-e-de-servicos-em-geral-exceto-osestabelecimentos-que-menciona-para-enfrentamento-da-emergencia-de-saude-publica-de-importancia-internacionaldecorrente-do-novo-coronavirus-covid-19-no-municipio-de-porto-alegre?q=covid-19

https://leismunicipais.com.br/a/rs/p/porto-alegre/decreto/2020/2051/20506/decreto-n-20506-2020-estabelecemedidas-para-os-estabelecimentos-shoppings-centers-e-centros-comerciais-para-enfrentamento-da-emergenciade-saude-publica-de-importancia-internacional-decorrente-do-novo-coronavirus-covid-19-no-municipio-de-portoalegre? $\mathrm{q}=$ covid -19

https://leismunicipais.com.br/a/rs/p/porto-alegre/decreto/2020/2051/20505/decreto-n-20505-2020-decreta-situacaode-emergencia-e-estabelece-medidas-para-os-estabelecimentos-restaurantes-bares-casas-noturnas-e-outros-para-enfrentamento-da-emergencia-de-saude-publica-de-importancia-internacional-decorrente-do-novo-coronavirus-covid19-no-municipio-de-porto-alegre?q=covid-19

https://leismunicipais.com.br/a/rs/p/porto-alegre/decreto/2020/2051/20502/decreto-n-20502-2020-inclui-os-incsiii-e-iv-no-art-1-e-revoga-0-art-2-do-decreto-n-20499-de-16-de-marco-de-2020-que-dispoe-sobre-medidas-aserem-adotadas-para-o-enfrentamento-da-emergencia-de-saude-publica-decorrente-do-novo-coronavirus-covid-19-nomunicipio-de-porto-alegre?q=covid-19

https://www1.folha.uol.com.br/cotidiano/2020/04/alunos-recebem-refeicao-diaria-cestas-basicas-e-vouchers-comomerenda.shtml

https://gauchazh.clicrbs.com.br/coronavirus-servico/noticia/2020/04/voluntarios-distribuem-mais-de-20-toneladas-dealimentos-em-esteio-ck95tra2f003e017ny26nqaid.html

https://g1.globo.com/rs/rio-grande-do-sul/noticia/2020/03/28/prefeitura-de-porto-alegre-realiza-higienizacao-emespacos-publicos.ghtml

https://www.jornaldocomercio.com/_conteudo/especiais/coronavirus/2020/04/732567-prefeitura-de-porto-alegreanuncia-medidas-em-apoio-aos-contribuintes.html

\section{Porto Seguro-BA}

http://www.acessoinformacao.com.br/ba/portoseguro/wp-includes/ExternalApps/downloader. php?hurl=aHROcDovL2RvZWOub3JnLmJyL2JhL3BvcnRvc2VndXJvL2FycXVpdm9ZL2Rvd25sb2FkLzlyMTQyZDY2YTBmYm M5ZTFmNjc3NTE1YWEZODBkMzA2LORPRS1iYV9wb3J0b3NIZ3Vyby1IZC40LjIONC1hbm8uMi5wZGY\%3D

http://www.acessoinformacao.com.br/ba/portoseguro/wp-includes/ExternalApps/downloader. php?hurl=aHROcDovL2RvZWOub3JnLmJyL2JhL3BvcnRvc2VndXJvL2FycXVpdm9zL2Rvd25sb2FkL2NiYmY5ZjU2ZGRmYm VjNmVmZDU2NGRiNzdm0TI2NDYwLORPRS1iYV9wb3J0b3NIZ3Vyby1IZC40Lj11NC1hbm8uMi5wZGY\%3D http://www.acessoinformacao.com.br/ba/portoseguro/wp-includes/ExternalApps/downloader. php?hurl=aHROcDovL2RvZWOub3JnLmJyL2JhL3BvcnRvc2VndXJvL2FycXVpdm9zL2Rvd25sb2FkL2NIZDA1YWVkMjMON 2FkOTQxOTA50GYwZDAwMjA2Njg2LORPRS1iYV9wb3J0b3NIZ3Vyby1IZC40LjI2MC1hbm8uMi5wZGY\%3D http://www.bahiadiaadia.com/noticias/extremo-sul/9570/prefeita-de-porto-seguro-decreta-estado-de-calamidade-eprorroga-quarentena-05-04-2020/ 


\section{Fontes dos dados qualitativos por município}

https://www.bahiadiaadia.com/noticias/informe/9608/estado-de-calamidade-e-reconhecido-em-porto-seguro-e-mais-85municipios-14-04-2020/

https://www.bbc.com/portuguese/brasil-51921267

https://g1.globo.com/ba/bahia/noticia/2020/04/15/covid-19-turismo-em-porto-seguro-e-afetado-e-sindicato-diz-quemais-de-80percent-dos-funcionarios-de-hoteis-foram-demitidos.ghtml

https://g1.globo.com/ba/bahia/noticia/2020/04/08/instituicoes-de-caridade-e-aldeia-indigena-no-sul-da-bahia-recebemcerca-de-2-mil-cestas-basicas.ghtml

\section{Prado-BA}

https://g1.globo.com/ba/bahia/noticia/2020/03/18/governo-da-ba-suspende-aulas-em-escolas-particulares-efuncionamento-do-transporte-intermunicipal-como-medida-ao-coronavirus.ghtml

https://noticias.uol.com.br/cotidiano/ultimas-noticias/2020/03/20/desespero-dos-ambulantes-comercio-na-bahia-tentase-adaptar-ao-coronavirus.htm

https://www.facebook.com/prefeituraprado/

\section{Rancho Queimado-SC}

http://www.rq.sc.gov.br/midias/imagens/1584654701.pdf

http://www.rq.sc.gov.br/midias/imagens/1584549951.pdf

http://www.rq.sc.gov.br/midias/imagens/1587044389.pdf

https://www.facebook.com/CleciPrefeita15/

http://g1.globo.com/sc/santa-catarina/videos/v/nota-rancho-queimado-tem-dois-casos-confirmados-decoronavirus/8416400/

\section{Recife-PE}

https://g1.globo.com/pe/pernambuco/noticia/2020/03/17/coronavirus-recife-proibe-eventos-com-mais-de-50-pessoase-reduz-em-50percent-capacidade-de-bares-e-restaurantes.ghtml

https://g1.globo.com/pe/pernambuco/noticia/2020/03/21/prefeitura-do-recife-diz-que-vai-manter-servicos-essenciaisdurante-pandemia-do-novo-coronavirus.ghtml

https://tvjornal.ne10.uol.com.br/noticias/2020/03/26/prefeitura-do-recife-antecipa-pagamento-do-iptu-de-2021-devidoao-novo-coronavirus-186007

https://blogs.ne10.uol.com.br/jamildo/2020/04/13/empresarios-pernambucanos-dao-inicio-a-acao-conjunta-desolidariedade-pela-populacao-do-estado/

https://g1.globo.com/pe/pernambuco/noticia/2020/03/19/prevencao-ao-coronavirus-pernambuco-determinafechamento-de-shoppings-bares-restaurantes-e-lanchonetes.ghtml

https://g1.globo.com/pe/pernambuco/noticia/2020/04/01/recife-prorroga-por-90-dias-prazo-para-o-pagamento-doimposto-sobre-servicos-devido-a-pandemia.ghtml

https://jc.ne10.uol.com.br/economia/2020/04/5604505-coronavirus--confira-medidas-adotadas-pela-prefeitura-dorecife-para-minimizar-prejuizos-das-empresas.html https://leismunicipais.com.br/a/pe/r/recife/decreto/2020/3358/33577/decreto-n-33577-2020-prorroga-a-suspensaodas-atividades-das-escolas-publicas-municipais-e-das-escolas-e-universidades-particulares-situadas-no-municipio-dorecife-e-disciplina-a-entrega-de-cesta-basica-e-material-de-higiene-para-as-familias-dos-estudantes-das-unidadeseducacionais-publicas-da-rede-municipal-de-ensino-do-recife-no-referido-periodo?q=covid-19

\section{Rio Branco-AC}

https://www.legisweb.com.br/legislacao/?id=392866

https://www.legisweb.com.br/legislacao/?id=392704 


\section{Fontes dos dados qualitativos por município}

https://g1.globo.com/ac/acre/noticia/2020/03/18/prefeita-decreta-emergencia-apos-casos-de-covid-19-e-recomendahigienizacao-de-onibus-em-rio-branco.ghtml

http://www.oriobranco.net/noticia/geral/17-03-2020-acre-e-mais-um-estado-a-suspender-aulas-por-conta-do-coronavirus https://g1.globo.com/ac/acre/noticia/2020/03/20/prevencao-a-covid-19-governo-do-ac-determina-fechamento-deshopping-bares-restaurantes-e-lanchonetes.ghtml

https://g1.globo.com/ac/acre/noticia/2020/04/08/prefeitura-de-rio-branco-mantem-aulas-suspensas-ate-30-de-abrilem-combate-ao-coronavirus.ghtml

https://g1.globo.com/ac/acre/noticia/2020/03/27/prefeitura-prorroga-suspensao-de-aulas-e-medidas-de-combate-acovid-19-em-rio-branco.ghtml

https://g1.globo.com/ac/acre/noticia/2020/04/16/prefeitura-sanciona-isencao-de-iptu-iss-e-outros-tributos-comomedida-de-combate-a-covid-19.ghtml

\section{Rio de Janeiro-RJ}

http://prefeitura.rio/casa-civil/decreto-da-prefeitura-do-rio-determina-medidas-para-0-combate-a-pandemia-do-novocoronavirus/

http://smaonline.rio.rj.gov.br/legis_consulta/61039DECRET0\%2047263_2020.pdf

https://exame.abril.com.br/brasil/rio-vai-distribuir-cestas-basicas-para-parte-de-alunos-da-rede-municipal/ https://agenciabrasil.ebc.com.br/saude/noticia/2020-04/prefeitura-do-rio-mantem-escolas-fechadas-ate-30-de-abril http://prefeitura.rio/cidade/coronavirus-secretaria-municipal-de-educacao-distribui-cestas-basicas-para-alunos-queforam-almocar-nas-escolas/

https://exame.abril.com.br/brasil/rio-vai-distribuir-cestas-basicas-para-parte-de-alunos-da-rede-municipal/ https://g1.globo.com/rj/rio-de-janeiro/noticia/2020/03/22/prefeitura-do-rio-determina-fechamento-do-comercio-a-partirde-terca-feira-para-conter-coronavirus.ghtml

https://noticias.uol.com.br/cotidiano/ultimas-noticias/2020/04/08/crivella-decreta-estado-de-calamidade-publica-no-riopor-coronavirus.htm

https://agenciabrasil.ebc.com.br/saude/noticia/2020-03/rio-de-janeiro-cria-gabinete-de-crise-para-novo-coronavirus

\section{Rio Verde-GO}

https://www.opopular.com.br/noticias/economia/entenda-0-que-abre-e-0-que-fecha-em-rio-verde-1.2018705 http://acessoainformacao.rioverde.go.gov.br/cidadao/legislacao/decreto/id=6475 https://www.rioverde.go.gov.br/wp-uploads/2020/04/Decreto-Consolidado-743-1.pdf https://www.opopular.com.br/noticias/economia/prefeitura-de-rio-verde-prorroga-mais-uma-vez-0-prazo-parapagamento-de-alvarás-e-iptu-confira-data-1.2035719

https://www.rioverde.go.gov.br/wp-uploads/2020/04/Decreto-748-2.pdf https://www.rioverde.go.gov.br/wp-uploads/2020/04/Decreto-840-1-1.pdf https://www.rioverde.go.gov.br/wp-uploads/2020/04/Decreto-764.pdf https://www.rioverde.go.gov.br/wp-uploads/2020/04/organograma_COESEC-RV-1.pdf https://www.rioverde.go.gov.br/wp-uploads/2020/04/DECRET0-N-810-1.pdf

\section{Salvador-BA}

https://leismunicipais.com.br/a/ba/s/salvador/lei-ordinaria/2020/952/9517/lei-ordinaria-n-9517-2020-institui-0-auxiliosalvador-por-todos-no-ambito-da-assistencia-social-com-o-objetivo-de-garantir-aos-cidadaos-que-nao-tem-empregoformal-as-condicoes- minimas-de-sobrevivencia-diante-da-pandemia-de-coronavirus-na-forma-que-indica-e-da-outrasprovidencias?q=covid -19

https://leismunicipais.com.br/a/ba/s/salvador/decreto/2020/3227/32268/decreto-n-32268-2020-declara-situacao-deemergencia-no-municipio-de-salvador-e-define-outras-medidas-para-o-enfrentamento-da-pandemia-decorrente-docoronavirus?q=covid -19 


\section{Fontes dos dados qualitativos por município}

https://leismunicipais.com.br/a/ba/s/salvador/decreto/2020/3228/32280/decreto-n-32280-2020-define-medidascomplementares-para-o-enfrentamento-da-pandemia-decorrente-do-coronavirus?q=covid-19

https://g1.globo.com/ba/bahia/noticia/2020/03/30/trabalhadores-informais-de-salvador-receberao-mais-de-r-100milhoes-em-ajuda-apos-serem-impactados-pelo-coronavirus-saiba-mais.ghtml

https://leismunicipais.com.br/a/ba/s/salvador/decreto/2020/3229/32288/decreto-n-32288-2020-cria-0-centro-deoperacoes-de-emergencias-para-resposta-ao-novo-coronavirus-coe-ncov? $q=$ covid-19

https://www.correio24horas.com.br/noticia/nid/correcao-auxilio-de-r-270-a-informais-nao-tera-novos-cadastros/ https://www.ibahia.com/salvador/detalhe/noticia/forca-tarefa-da-prefeitura-interditou-91-estabelecimentos-no-final-desemana-em-salvador/

https://g1.globo.com/ba/bahia/noticia/2020/04/01/convenio-entre-prefeitura-e-fiocruz-amplia-numero-de-testes-paracoronavirus-em-salvador.ghtml

https://leismunicipais.com.br/a/ba/s/salvador/decreto/2020/3228/32280/decreto-n-32280-2020-define-medidascomplementares-para-o-enfrentamento-da-pandemia-decorrente-do-coronavirus

https://g1.globo.com/ba/bahia/noticia/2020/03/26/comercio-de-rua-fechado-e-higienizacao-das-principais-vias-vejanovas-medidas-contra-o-coronavirus-em-salvador.ghtml

https://g1.globo.com/ba/bahia/noticia/2020/04/16/distribuicao-de-cestas-basicas-para-alunos-atrasa-em-salvador-esecretario-diz-que-causa-foi-problema-logistico.ghtml

https://g1.globo.com/bom-dia-brasil/noticia/2020/04/06/ambulantes-e-trabalhadores-informais-de-salvador-receberaoajuda-financeira-devido-ao-coronavirus-saiba-mais.ghtml

https://g1.globo.com/ba/bahia/noticia/2020/04/10/em-rede-social-prefeito-de-salvador-anuncia-ampliacao-de-auxiliopara-taxistas-e-motoristas-de-aplicativo.ghtml

https://g1.globo.com/ba/bahia/noticia/2020/04/14/coronavirus-hospitais-de-campanha-somam-673-leitos-em-salvadore-lauro-de-freitas.ghtml

https://www.correio24horas.com.br/noticia/nid/campanha-salvador-solidaria-ganha-parceria-da-cdl-salvador-e-fcdl-bahia/ https://g1.globo.com/ba/bahia/noticia/2020/03/28/medida-que-suspende-funcionamento-do-comercio-de-rua-desalvador-comeca-neste-sabado-por-causa-da-covid-19.ghtml

\section{Santana de Parnaíba-SP}

https://leismunicipais.com.br/a/sp/s/santana-de-parnaiba/decreto/2020/436/4354/decreto-n-4354-2020-declaraestado-de-calamidade-publica-no-municipio-de-santana-de-parnaiba-e-dispoe-sobre-a-adocao-de-novas-medidas-paraintensificar-0-combate-ao-novo-coronavirus-covid-19?q=covid-19

https://leismunicipais.com.br/a/sp/s/santana-de-parnaiba/decreto/2020/436/4353/decreto-n-4353-2020-autoriza-os-assecretarios-as-municipais-com-0-suporte-dos-diretores-dos-departamentos-vinculados-a-suas-respectivas-secretarias-aadotarem-imediatamente-planos-de-trabalhos-que-estipulem-as-providencias-necessarias-para-execucao-de-atividadesa-distancia-por-meio-virtual-telefonico-escritorio-remoto-home-office-qualquer-outro-modelo-nao-presencial-ou-sistemade-revezamento-por-todos-os-servidores-publicos-cujas-atribuicoes-possam-ser-exercidas-dessa-forma-em-decorrenciado-novo-coronavirus-covid-19?q=covid-19

https://leismunicipais.com.br/a/sp/s/santana-de-parnaiba/decreto/2020/435/4350/decreto-n-4350-2020-dispoe-sobrea-adocao-no-ambito-da-administracao-publica-direta-e-indireta-de-medidas-temporarias-e-emergenciais-de-prevencao-de-contagio-pelo-coronavirus-covid-19?q=covid-19 


\section{Fontes dos dados qualitativos por município}

https://leismunicipais.com.br/a/sp/s/santana-de-parnaiba/decreto/2020/435/4347/decreto-n-4347-2020-declaraestado-de-emergencia-na-saude-publica-no-municipio-de-santana-de-parnaiba-em-razao-de-surto-da-doencarespiratoria-coronavirus-covid-19?q=covid-19

https://correiopaulista.com/santana-de-parnaiba-tera-tres-hospitais-de-campanha/

\section{Santo André-SP}

https://www.abcdoabc.com.br/santo-andre/noticia/covid-19-boletim-santo-andre-30-3-99238

http://www3.santoandre.sp.gov.br/parquetecnologico/index.php/especial-coronavirus/

https://www.abcdoabc.com.br/santo-andre/noticia/santo-andre-lanca-comite-contingencia-coronavirus-98481 https://g1.globo.com/sp/sao-paulo/noticia/2020/04/15/coronavirus-abc-amplia-funcionamento-de-postos-decombustiveis-e-autoriza-bancas-de-jornais-na-quarentena.ghtml https://g1.globo.com/sp/sao-paulo/noticia/2020/04/18/coronavirus-prefeitura-de-santo-andre-restringe-acesso-a-vilade-paranapiacaba-no-abc.ghtml https://g1.globo.com/sp/sao-paulo/noticia/2020/03/22/prefeitura-de-santo-andre-determina-fechamento-de-comerciona-cidade-a-partir-desta-segunda.ghtml https://g1.globo.com/sp/sao-paulo/noticia/2020/04/15/santo-andre-inaugura-hospital-de-campanha-com-180-leitosem-centro-esportivo.ghtml https://www.abcdoabc.com.br/santo-andre/noticia/covid-19-boletim-santo-andre-22-4-100376 https://www.abcdoabc.com.br/santo-andre/noticia/santo-andre-prorroga-suspensao-aulas-fechamento-parques-ate-19abril-99522

https://www.abcdoabc.com.br/santo-andre/noticia/santo-andre-levara-alimento-produtos-limpeza-familias-alunos-redemunicipal-99130

https://www2.santoandre.sp.gov.br/index.php/noticias/item/13482-santo-andre-cria-fundo-especial-de-combate-aocoronavirus

\section{São Bernardo do Campo-SP}

https://abcreporter.com.br/2020/04/21/com-cartao-merenda-escolar-sao-bernardo-vai-oferecer-auxilio-alimentacao-a82-mil-alunos/

https://www.abcdoabc.com.br/sao-bernardo/noticia/sao-bernardo-anuncia-mobilizacao-cria-comite-combate-aocoronavirus-96396

https://www.abcdoabc.com.br/sao-bernardo/noticia/prefeitura-sao-bernardo-inicia-amanha-paralisacao-completa-ensinomunicipal-98761

https://agora.folha.uol.com.br/sao-paulo/2020/04/prefeitura-de-sao-bernardo-vai-pagar-auxilio-alimentacao-de-r-85-poraluno-durante-quarentena.shtml

https://www.abcdoabc.com.br/sao-bernardo/noticia/sao-bernardo-inicia-distribuicao-merenda-solidaria-99408 https://www.abcdoabc.com.br/sao-bernardo/noticia/wheaton-realiza-doacao-cestas-basicas-produtos-higiene-abc-99189 https://www.abcdoabc.com.br/sao-bernardo/noticia/sao-bernardo-fecha-331-estabelecimentos-comerciais-pordescumprimento-normas-99123

\section{São Caetano do Sul-SP}

http://diariooficial.saocaetanodosul.sp.gov.br/download/VisualizadorDocumento.aspx?doclD=798 http://diariooficial.saocaetanodosul.sp.gov.br/download/VisualizadorDocumento.aspx?doclD=778 http://diariooficial.saocaetanodosul.sp.gov.br/download/VisualizadorDocumento.aspx?doclD=776 http://diariooficial.saocaetanodosul.sp.gov.br/download/VisualizadorDocumento.aspx?doclD=774 https://abcreporter.com.br/2020/03/30/sao-caetano-entregara-alimentos-a-alunos-de-baixa-renda/ 


\section{Fontes dos dados qualitativos por município}

http://diariooficial.saocaetanodosul.sp.gov.br/download/VisualizadorDocumento.aspx?doclD=773

https://www.abcdoabc.com.br/sao-caetano/noticia/prefeitura-sao-caetano-entregara-cestas-alimentos-alunos-baixarenda-99096

http://www.informaabc.com.br/regional/id-903032/kit_merenda_sera_entregue_em_casa._confira_quem_pode_ receber_o_beneficio.

https://www.abcdoabc.com.br/sao-caetano/noticia/entenda-por-que-sao-caetano-se-tornou-exemplo-enfrentamentopandemia-99914

https://abcreporter.com.br/2020/04/20/prefeitura-de-sao-caetano-cria-hospital-de-campanha-para-receber-pacientescom-covid-19/

https://www.abcdoabc.com.br/sao-caetano/noticia/sao-caetano-intensifica-acoes-controle-covid-19-utilizacaodrones-100172

https://www.abcdoabc.com.br/sao-caetano/noticia/sao-caetano-recebe-doacoes-empresas-enfrentamentocoronavirus-99690

\section{São Paulo-SP}

https://g1.globo.com/sp/sao-paulo/noticia/2020/03/16/escolas-publicas-e-particulares-de-sp-comecam-suspensao-deaulas-nesta-segunda-feira-16.ghtml

https://leismunicipais.com.br/a/sp/s/sao-paulo/decreto/2020/5929/59283/decreto-n-59283-2020-declara-situacao-deemergencia-no-municipio-de-sao-paulo-e-define-outras-medidas-para-o-enfrentamento-da-pandemia-decorrente-docoronavirus? $\mathrm{q}=$ covid -19

https://leismunicipais.com.br/a/sp/s/sao-paulo/decreto/2020/5929/59285/decreto-n-59285-2020-suspende-0atendimento-presencial-ao-publico-em-estabelecimentos-comerciais-e-o-funcionamento-de-casas-noturnas-e-outrasvoltados-a-realizacao-de-festas-eventos-ou-recepcoes?q=covid-19

https://leismunicipais.com.br/a/sp/s/sao-paulo/decreto/2020/5929/59285/decreto-n-59285-2020-suspende-oatendimento-presencial-ao-publico-em-estabelecimentos-comerciais-e-o-funcionamento-de-casas-noturnas-e-outrasvoltados-a-realizacao-de-festas-eventos-ou-recepcoes?q=covid-19

https://leismunicipais.com.br/a/sp/s/sao-paulo/decreto/2020/5932/59313/decreto-n-59313-2020-oficializa-a-camara-deintegracao-institucional-que-objetiva-integrar-os-representantes-dos-poderes-constituidos-e-minimizar-os-impactos-decorrentesda-situacao-de-emergencia-e-do-estado-de-calamidade-publica-resultantes-da-pandemia-da-covid-19?q=covid-19

https://saude.estadao.com.br/noticias/geral,doria-e-covas-decretam-calamidade-publica-em-sp-porcoronavirus, 70003241481

https://exame.abril.com.br/brasil/estadio-do-pacaembu-vira-hospital-para-atender-vitimas-da-covid-19/

https://g1.globo.com/sp/sao-paulo/noticia/2020/03/25/prefeituras-empresarios-e-populacao-se-unem-em-meio-a-crisedo-coronavirus-para-ajudar-populacao-carente.ghtml

\section{Sete Lagoas-MG}

https://leismunicipais.com.br/a/mg/s/sete-lagoas/decreto/2020/624/6235/decreto-n-6235-2020-prorroga-em-caraterexcepcional-o-vencimento-dos-creditos-municipais-no-periodo-que-menciona-para-reducao-dos-impactos-sobrea-atividade-economica-do-municipio-de-sete-lagoas-em-viturde-das-medidas-de-enfrentamento-para-contencao-dapandemia-ocasionada-pelo-covid-19?q=covid-19 


\section{Fontes dos dados qualitativos por município}

https://leismunicipais.com.br/a/mg/s/sete-lagoas/decreto/2020/624/6232/decreto-n-6232-2020-institui-0-gabinetegestor-da-crise-do-coronavirus-covid-19-no-municipio-de-sete-lagoas?q=covid-19

https://leismunicipais.com.br/a/mg/s/sete-lagoas/decreto/2020/624/6231/decreto-n-6231-2020-dispoe-sobremedidas-de-emergencia-em-saude-publica-no-municipio-de-sete-lagoas-em-complemento-ao-decreto-n-6227-2020que-declara-situacao-de-emergencia-em-saude-publica-no-municipio-de-sete-lagoas-e-dispoe-sobre-medidas-deenfrentamento-da-pandemia-provocada-pelo-coronavirus-covid-19?q=covid-19

https://leismunicipais.com.br/a/mg/s/sete-lagoas/decreto/2020/623/6227/decreto-n-6227-2020-declara-situacao-deemergencia-em-saude-publica-no-municipio-de-sete-lagoas-e-dispoe-sobre-medidas-de-enfrentamento-da-pandemiaprovocada-pelo-coronavirus-covid-19?q=covid-19

https://g1.globo.com/mg/minas-gerais/noticia/2020/04/01/coronavirus-sete-lagoas-reabre-comercio-em-bhfuncionamento-continua-suspenso.ghtml

https://setelagoas.com.br/noticias/cidade/61456-assistencia-social-de-sete-lagoas-orienta-sobre-entrega-de-cestasbasicas-e-possivel-beneficio-da-uniao

https://leismunicipais.com.br/a/mg/s/sete-lagoas/decreto/2020/622/6227/decreto-n-6227-2020-declara-situacao-deemergencia-em-saude-publica-no-municipio-de-sete-lagoas-e-dispoe-sobre-medidas-de-enfrentamento-da-pandemiaprovocada-pelo-coronavirus-covid-19

http://www.setelagoas.mg.gov.br/detalhe-da-materia/info/prefeitura-fiscaliza-estabelecimentos-comerciais-paracumprimento-de-medidas-contra-0-coronavirus/57532

\section{Uberlândia-MG}

https://leismunicipais.com.br/a/mg/u/uberlandia/decreto/2020/1853/18523/decreto-n-18523-2020-institui-0-comitemunicipal-de-enfrentamento-ao-covid-19-e-designa-membros?q=covid-19

https://leismunicipais.com.br/a/mg/u/uberlandia/decreto/2020/1856/18553/decreto-n-18553-2020-declara-situacaode-emergencia-no-municipio-de-uberlandia-e-define-outras-medidas-para-o-enfrentamento-ao-novo-coronavirus-covid$19 ? q=$ covid -19

https://leismunicipais.com.br/a/mg/u/uberlandia/decreto/2020/1859/18582/decreto-n-18582-2020-dispoe-sobreforca-tarefa-temporaria-e-integrada-para-o-exercicio-da-fiscalizacao-de-estabelecimentos-e-atividades-quanto-ao-cumprimento-de-normas-e-diretrizes-estabelecidas-para-o-enfrentamento-do-novo-coronavirus-covid-19-no-ambito-domunicipio-de-uberlandia?q=covid-19

https://leismunicipais.com.br/a/mg/u/uberlandia/decreto/2020/1859/18583/decreto-n-18583-2020-declara-estado-decalamidade-publica-no-municipio-de-uberlandia-em-decorrencia-da-pandemia-do-novo-coronavirus-covid-19?q=covid-19 https://g1.globo.com/mg/triangulo-mineiro/noticia/2020/03/20/coronavirus-prefeitura-determina-fechamento-de-partedo-comercio-em-uberlandia.ghtml

https://g1.globo.com/mg/triangulo-mineiro/noticia/2020/03/24/prefeitura-de-uberlandia-volta-atras-e-fecha-totalmenteas-escolas.ghtml

https://www.uberlandia.mg.gov.br/2020/04/06/estudantes-cadastrados-no-bolsa-familia-recebem-kit-alimentacao/ https://g1.globo.com/mg/triangulo-mineiro/noticia/2020/03/23/combate-ao-coronavirus-empresarios-de-uberlandia-seunem-para-doar-equipamentos-e-dinheiro-a-hospitais.ghtml

Nota: Todos os endereços foram acessados entre 16 e 18 de abril de 2020.

Fonte: Elaborado pelos autores. 
RAP | 0 surto da COVID-19 e as respostas da administração municipal: munificência de recursos, vulnerabilidade social e eficácia de ações públicas

\section{QUADRO A3 PRESENÇA DE DISTRIBUIÇÃO DE MERENDA ESCOLAR POR MUNICÍPIO}

\begin{tabular}{|c|c|}
\hline Município & Merenda escolar? \\
\hline Anápolis-G0 & Não \\
\hline Aquiraz-CE & Não \\
\hline Barra Mansa-RJ & Não \\
\hline Belo Horizonte-MG & Sim \\
\hline Belo Jardim-PE & Sim \\
\hline Braço do Norte-SC & Não \\
\hline Campo Bom-RS & Sim \\
\hline Campo Grande-MS & Sim \\
\hline Campo Largo-PR & $\operatorname{Sim}$ \\
\hline Carapicuíba-SP & Sim \\
\hline Caxias do Sul-RS & Sim \\
\hline Cianorte-PR & Não \\
\hline Coronel Fabriciano-MG & Não \\
\hline Curitiba-PR & Sim \\
\hline Divinópolis-MG & Não \\
\hline Feira de Santana-BA & Não \\
\hline Ferraz de Vasconcelos-SP & Sim \\
\hline Florianópolis-SC & $\operatorname{Sim}$ \\
\hline Fortaleza-CE & $\operatorname{Sim}$ \\
\hline Foz do Iguaçu-PR & $\operatorname{Sim}$ \\
\hline Goiânia-G0 & $\operatorname{Sim}$ \\
\hline Guarulhos-SP & $\operatorname{Sim}$ \\
\hline Ipatinga-MG & $\operatorname{Sim}$ \\
\hline Jaboatão dos Guararapes-PE & $\operatorname{Sim}$ \\
\hline Joinville-SC & Não \\
\hline Juiz de Fora-MG & Não \\
\hline Londrina-PR & Sim \\
\hline Maceió-AL & Não \\
\hline Manaus-AM & Sim \\
\hline Maringá-PR & Não \\
\hline Mauá-SP & Não \\
\hline Natal-RN & Sim \\
\hline
\end{tabular}




\begin{tabular}{lc} 
Municíio & Merenda escolar? \\
\hline Niterói-RJ & Sim \\
Nova Lima-MG & Sim \\
Patrocínio-MG & Não \\
Pinhais-PR & Sim \\
Porto Alegre-RS & Sim \\
Porto Seguro-BA & Não \\
Prado-BA & Sim \\
Rancho Queimado-SC & No \\
Recife-PE & Sim \\
Rio Branco-AC & Não \\
Rio de Janeiro-RJ & Sim \\
Rio Verde-GO & Não \\
Salvador-BA & Sim \\
Santana de Parnaíba-SP & Não \\
Santo André-SP & Sim \\
São Bernardo do Campo-SP & Sim \\
São Caetano do Sul-SP & Sim \\
São Paulo-SP & Não \\
Sete Lagoas-MG & Não \\
Uberlândia-MG & Sim \\
\hline
\end{tabular}

Fonte: Elaborado pelos autores.

\section{QUADRO A4 PRESENÇA DE PROGRAMAS DE AUXÍLIO POR MUNICÍPIO}

\section{Descrição de programas de auxílio por município}

\section{Anápolis-GO}

[Distribuição de cesta básica.]

\section{Aquiraz-CE}

[Em virtude da pandemia da COVID-19, informa a aprovação da Lei $N^{\circ}$ 1.355, de 07 de abril de 2020, que estabelece a Concessão de Parcelamento Especial de Débitos Fiscais - REFIS.][Só na última segunda-feira (6), as equipes distribuíram 125 cestas básicas para famílias atingidas pela pandemia. Desta vez, a ação aconteceu na Caponga da Bernarda, Vila Cabral, Sítios Novos, Comunidade do Barreiras e Conjunto Vitória.] 
Descrição de programas de auxílio por município

\section{Barra Mansa-RJ}

[A Prefeitura de Barra Mansa, através da Secretaria de Assistência Social e Direitos Humanos, orienta a população sobre a distribuição de 13 mil cestas básicas, que serão entregues às famílias com maior vulnerabilidade em função da quarentena causada pelo novo coronavírus.]

\section{Belo Horizonte-MG}

Não encontrado.

\section{Belo Jardim-PE}

Não encontrado.

\section{Braço do Norte-SC}

[A partir desta terça-feira, 31 de março, o Município de Braço do Norte passa a contar com um reforço no auxílio alimentação para famílias de baixa renda e pessoas momentaneamente privadas de seus trabalhos por conta da pandemia COVID-19.]

\section{Campo Bom-RS}

[Cesta básica. A entrega dos itens é uma ação permanente da prefeitura, mas que em virtude da quarentena do Coronavírus teve sua procura mais que triplicada. A maior parte dos beneficiados são famílias já inscritas no cadastro social da prefeitura e também desempregados, autônomos, trabalhadores informais além de pessoas empregadas que perderam seu potencial de compra tendo em vista a redução das jornadas de trabalho em algumas empresas.][A primeira ação estabelecida pelo comitê é a doação de 10 mil cestas básicas à comunidade campobonense. 0 prefeito Luciano Orsi presidiu a teleconferência junto com o diretor da Arezzo \&Co.]

\section{Campo Grande-MS}

Não encontrado.

\section{Campo Largo-PR}

[Auxílio calamidade pela distribuição de cestas básicas.]

\section{Carapicuíba-SP}

Não encontrado.

\section{Caxias do Sul-RS}

Não encontrado.

\section{Cianorte-PR}

Não encontrado.

\section{Coronel Fabriciano-MG}

Não encontrado.

\section{Curitiba-PR}

Não encontrado.

\section{Divinópolis-MG}

Não encontrado. 
Descrição de programas de auxílio por município

\section{Feira de Santana-BA}

[A Prefeitura de Feira de Santana, a $100 \mathrm{~km}$ de Salvador, vai distribuir cestas básicas e material de higiene e limpeza às famílias em situação de pobreza e extrema pobreza, que estão inscritas no Cadastro Único (CADÚNICO).][Foi iniciada pela Prefeitura de Feira, no último dia 30/03, a distribuição de cerca de oito mil cestas básicas para famílias em situação de extrema pobreza. A iniciativa emergencial do auxílio alimentação visa amenizar as dificuldades enfrentadas por milhares de feirenses, que se agravaram em função da necessidade de isolamento social por causa da pandemia do coronavírus (COVID-19).]

\section{Ferraz de Vasconcelos-SP}

Não encontrado.

\section{Florianópolis-SC}

[Será ampliado o valor destinado ao Programa Juro Zero Floripa, para atendimento micro empreendedores individuais MEl e microempreendedores - ME.]

\section{Fortaleza-CE}

[A medida busca auxiliar com $\mathrm{R} \$ 100$ os profissionais autônomos, como feirantes, ambulantes, permissionários e artesãos cadastrados na Prefeitura de Fortaleza. Ao todo 31.917 profissionais serão beneficiados com a ajuda por dois meses.][Permissionários de box ou mercados públicos vão ser isentos de pagamentos do local, em retroativo ao dia do anúncio do decreto de fechamento do comércio, em 19 de março]Pelos próximos três meses, serão distribuídas 138 mil cestas básicas para famílias mais vulneráveis de Fortaleza, por meio do projeto "Comida em Casa".]

\section{Foz do Iguaçu-PR}

[Programa de Microfinanças Foz Juro Zero.]

\section{Goiânia-GO}

Não encontrado.

\section{Guarulhos-SP}

Não encontrado.

\section{Ipatinga-MG}

Não encontrado.

\section{Jaboatão dos Guararapes-PE}

Não encontrado.

\section{Joinville-SC}

[As cestas básicas estão sendo entregues para famílias inscritas no Cadastro Único. Quem não estiver inscrito deve entrar em contato pelos telefones (47) 3433-8659, (47) 3432-8544, (47) 3433-5975 ou (47) 3432-8543.]

\section{Juiz de Fora-MG}

Não encontrado.

\section{Londrina-PR}

Não encontrado.

\section{Maceió-AL}

Não encontrado. 
Descrição de programas de auxílio por município

\section{Manaus-AM}

[Fica o Poder Executivo autorizado a conceder bolsa-auxilio emergencial, de caráter suplementar e provisório, pelo prazo de dois meses, com recursos do Tesouro Municipal, para as pessoas físicas que atuem como comerciantes e prestadores de serviços informais ou ambulantes dos Centros de Comércio Popular apoiados pela Prefeitura de Manaus, no valor mensal de $\mathrm{R} \$ 300,00$ (trezentos reais), destinada a reduzir os déficit operacionais da suspensão das atividades dos Centros de Comércio Popular, em razão da pandemia ocasionada pelo novo Coronavírus (COVID-19) em Manaus.] [Fica suspensa a interrupção do fornecimento dos serviços públicos de água e esgotamento sanitário prestados pela Concessionária Águas de Manaus, em função de inadimplemento do consumidor, pelo prazo de 60 (sessenta) dias, a contar da data de publicação deste Decreto][0 valor da bolsa-auxílio emergencial será de $\mathrm{R} \$ 300,00$ (trezentos reais) mensais.]

\section{Maringá-PR}

[Cartão com R\$ 90; famílias que não têm Cadastro Único devem fazer o pedido por telefone exclusivo (notícia de 14/04).]

\section{Mauá-SP}

Não encontrado.

\section{Natal-RN}

Não encontrado.

\section{Niterói-RJ}

[Auxílio financeiro a ser dispensado pelo período de três meses aos Microempreendedores Individuais][proibido suspender 0 serviço de água no município de Niterói.][Dispõe sobre a criação de renda básica temporária para cidadãos do município de Niterói inscritos no CadÚnico][Dispõe sobre a concessão de auxílio emergencial aos permissionários do serviço de táxi e seus auxiliares, bem como aos prestadores de serviço de transporte escolar em virtude dos impactos sociais e econômicos da pandemia da COVID-19.]

\section{Nova Lima-MG}

Não encontrado.

\section{Patrocínio-MG}

Não encontrado.

\section{Pinhais-PR}

[Fica estabelecido o Programa de Benefício Financeiro Social Temporário aos catadores individuais do Município de Pinhais, afetados pela medida preventiva temporária de suspensão de coleta domiciliar de resíduos recicláveis, em razão da situação de emergência oriunda da Pandemia do Coronavírus (COVID-19).]

\section{Porto Alegre-RS}

Não encontrado.

\section{Porto Seguro-BA}

Não encontrado.

\section{Prado-BA}

Não encontrado. 
RAP | 0 surto da COVID-19 e as respostas da administração municipal: munificência de recursos, vulnerabilidade social e eficácia de ações públicas

Descrição de programas de auxílio por município

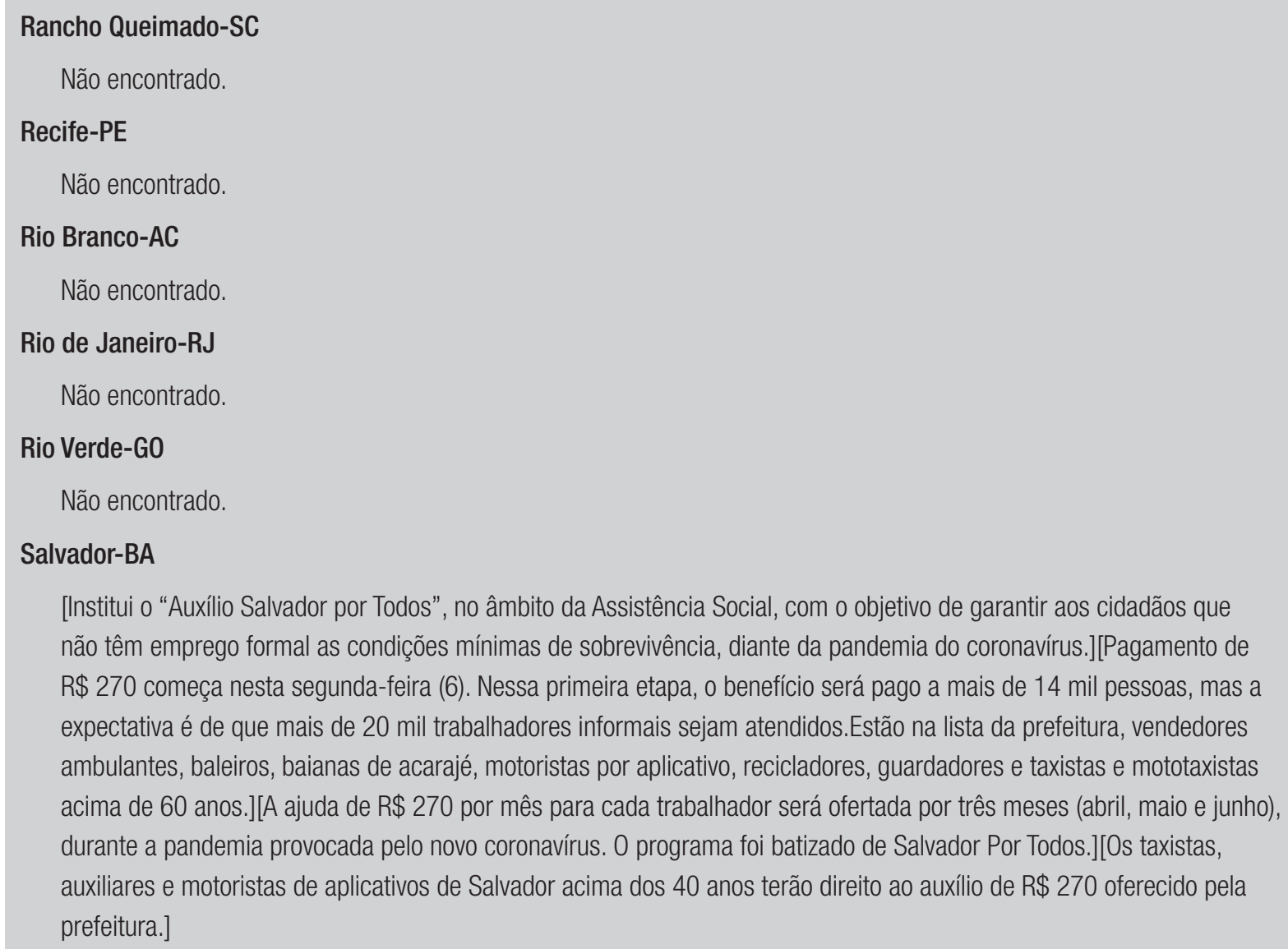

Não encontrado.

\section{Recife-PE}

Não encontrado.

\section{Rio Branco-AC}

Não encontrado.

\section{Rio de Janeiro-RJ}

Não encontrado.

\section{Rio Verde-GO}

Não encontrado.

\section{Salvador-BA}

[Institui o "Auxílio Salvador por Todos", no âmbito da Assistência Social, com o objetivo de garantir aos cidadãos que não têm emprego formal as condições mínimas de sobrevivência, diante da pandemia do coronavírus.][Pagamento de $\mathrm{R} \$ 270$ começa nesta segunda-feira (6). Nessa primeira etapa, o benefício será pago a mais de 14 mil pessoas, mas a expectativa é de que mais de 20 mil trabalhadores informais sejam atendidos.Estão na lista da prefeitura, vendedores ambulantes, baleiros, baianas de acarajé, motoristas por aplicativo, recicladores, guardadores e taxistas e mototaxistas acima de 60 anos.][A ajuda de $\mathrm{R} \$ 270$ por mês para cada trabalhador será ofertada por três meses (abril, maio e junho), durante a pandemia provocada pelo novo coronavírus. 0 programa foi batizado de Salvador Por Todos.][Os taxistas, auxiliares e motoristas de aplicativos de Salvador acima dos 40 anos terão direito ao auxílio de $\mathrm{R} \$ 270$ oferecido pela prefeitura.]

\section{Santana de Parnaíba-SP}

Não encontrado.

\section{Santo André-SP}

Não encontrado.

\section{São Bernardo do Campo-SP}

Não encontrado.

\section{São Caetano do Sul-SP}

Não encontrado.

\section{São Paulo-SP}

Não encontrado.

\section{Sete Lagoas-MG}

Não encontrado.

\section{Uberlândia-MG}

Não encontrado.

Fonte: Elaborado pelos autores. 


\section{QUADRO A5 PRESENÇA DE COLABORAÇÃO DENTRO DO SETOR PÚBLICO}

\section{Descrição das colaborações dentro do setor público}

\section{Anápolis-G0 \\ Não encontrado. \\ Aquiraz-CE \\ Não encontrado. \\ Barra Mansa-RJ \\ Não encontrado. \\ Belo Horizonte-MG \\ Não encontrado.}

\section{Belo Jardim-PE}

[Comitê Municipal de Resposta Rápida ao Coronavírus.]

\section{Braço do Norte-SC}

[Comitê Consultivo de Gerenciamento de Crise da COVID-19.][Representantes da Prefeitura, Ministério Público, Poder Judiciário, Polícias Civil e Militar, Ordem dos Advogados do Brasil e Corpo de Bombeiros se reuniram na tarde desta terça-feira, 17, no Gabinete do Prefeito para a criação de um comitê de gerenciamento. A ideia é manter a integração entre os órgãos para otimizar o combate a COVID-19 (Coronavírus).]

\section{Campo Bom-RS}

[Comitê de Controle de Riscos da COVID-19, o qual será de composição mista entre servidores do Município e membros da sociedade.]

\section{Campo Grande-MS}

[Cria o comitê municipal de enfrentamento e prevenção à COVID-19.]

\section{Campo Largo-PR}

[Comitê de Gestão de Crise Interinstitucional para definição de um plano de ação, prevenção e de contingência em resposta a pandemia do coronavírus - COVID-19, baseado na secretaria de saúde.]

\section{Carapicuíba-SP}

[Fica instituída a Comissão Administrativa de Enfrentamento ao Coronavírus, com a atribuição de assessorar o Chefe do Poder Executivo em assuntos de natureza administrativa relacionados à pandemia do Coronavírus - COVID-19, que será composta, inicialmente, por membros das Secretarias de Segurança, Saúde, Assuntos Jurídicos e Receita e Rendas.]

\section{Caxias do Sul-RS}

[0 Prefeito Flávio Cassina e o Vice-prefeito e secretário do Planejamento, Edio Elói Frizzo criaram nesta quinta-feira (12/03) o Gabinete de Crise para acompanhar de perto o andamento dos casos do Coronavírus na cidade. Além deles, compõe o grupo a Chefe de Gabinete e secretária de Governo, Grégora Fortuna dos Passos e os secretários da Saúde, Jorge Castro, da Educação, Flávia Vergani, de Recursos Humanos e Logística, Valéria Wormann e de Gestão e Finanças, Paulo Dahmer, além da presidente da FAS, Marlês Sebben.]

\section{Cianorte-PR}

[Fica criado o Comitê Técnico de Enfrentamento ao Coronavírus e Ética Médica, presidido pela Secretária Municipal da Saúde]. 
RAP | 0 surto da COVID-19 e as respostas da administração municipal: munificência de recursos, vulnerabilidade social e eficácia de ações públicas

\section{Descrição das colaborações dentro do setor público}

\section{Coronel Fabriciano-MG}

[0 Comitê de Crise com objetivo de centralizar e integrar ações do Município para garantir proteção e assistência à população.]

\section{Curitiba-PR}

[Gabinete Integrado de Acompanhamento à Epidemia do Novo Coronavírus (Giac-COVID-19) no Estado do Paraná. Além do Ministério Público do Paraná, compõem o gabinete integrado o Ministério Público Federal, o Ministério Público do Trabalho, o Conselho Nacional de Secretarias Municipais de Saúde (Conasems/PR) e o Conselho Nacional de Secretários Estaduais de Saúde (Conass/PR). Macrorregiões (Curitiba, Cascavel, Londrina e Maringá).]

\section{Divinópolis-MG}

Não encontrado.

\section{Feira de Santana-BA}

[Comitê Gestor Municipal de Controle ao Coronavírus.]

\section{Ferraz de Vasconcelos-SP}

[Foi instituído um comitê composto por todos os secretários municipais e o diretor de Comunicação Social, Fernando Felippe, por uma equipe da Saúde da cidade e presidido pelo chefe do executivo de Ferraz, que deverá direcionar as ações neste sentido.]

\section{Florianópolis-SC}

Não encontrado.

\section{Fortaleza-CE}

Não encontrado.

\section{Foz do Iguaçu-PR}

[Comitê Municipal de Controle e Prevenção da Dengue e COVID-19.]

\section{Goiânia-G0}

Não encontrado.

\section{Guarulhos-SP}

Não encontrado.

\section{Ipatinga-MG}

[Por iniciativa da Administração municipal de Ipatinga, foi realizada durante a manhã desta terça-feira (17) a primeira reunião do Comitê de Gestão de Crise, órgão criado para discutir com as autoridades do município medidas efetivas de prevenção para conter o avanço do novo Coronavírus no município, tendo em vista os riscos da propagação da doença por meio de transmissão local e comunitária. A formação do Comitê está embasada no Decreto de nº 9273/2020, publicado na última segunda-feira (16), que também estabeleceu no município o estado de emergência.]

\section{Jaboatão dos Guararapes-PE}

[Plano de Ações Intersetoriais Emergenciais e Estratégicas para atendimento do Plano de Contingência da COVID-19.]

\section{Joinville-SC}

[Cria Comissão Especial para examinar, acompanhar e opinar sobre a emergência de saúde pública de importância internacional relacionada ao coronavírus (COVID-19).] 


\section{Descrição das colaborações dentro do setor público}

\section{Juiz de Fora-MG}

[Fica criado o Comitê de Prevenção e Enfrentamento ao Coronavírus (COVID-19), sob a coordenação do Prefeito, com 0 objetivo de estabelecer e divulgar ações de prevenção à transmissão do vírus, composto por representantes dos seguintes órgãos:

I - Gabinete do Prefeito;

II - Secretaria de Saúde;

III - Secretaria de Educação;

IV - Secretaria de Desenvolvimento Social;

V - Secretaria de Administração e Recursos Humanos;

VI - Secretaria de Governo e;

VII - Procuradoria-geral do Município.]

[Diante da preocupação com a pandemia do novo coronavírus (SARS-CoV-2), a Universidade Federal de Juiz de Fora (UFJF) e a prefeitura da cidade anunciaram, na quarta-feira (15), o acordo de colaboração entre as partes no combate a propagação do vírus.][PJF e Governo Estadual criam força-tarefa para arrecadação voluntária de doações.]

\section{Londrina-PR}

[Diferentes órgão municipais participam do Coesp.][ [Gabinete Integrado de Acompanhamento à Epidemia do Novo Coronavírus (Giac-COVID-19) no Estado do Paraná. Além do Ministério Público do Paraná, compõem o gabinete integrado o Ministério Público Federal, o Ministério Público do Trabalho, o Conselho Nacional de Secretarias Municipais de Saúde (Conasems/PR) e o Conselho Nacional de Secretários Estaduais de Saúde (Conass/PR). macrorregiões (Curitiba, Cascavel, Londrina e Maringá).]

\section{Maceió-AL}

[0 Gabinete de Crise é composto pela Secretaria Municipal de Gestão (Semge), Procuradoria-Geral do Município (PGM), Secretaria Municipal de Saúde (SMS), Secretaria Municipal de Educação (Semed), Secretaria Municipal de Assistência Social (Semas), Secretaria Municipal de Comunicação (Secom), Secretaria Municipal de Segurança Comunitária e Convivio Social (Semscs) e Gabinete de Governança (GGov).]

\section{Manaus-AM}

Não encontrado.

\section{Maringá-PR}

[A Secretaria Municipal de Saúde criou ao menos quatro comissões voltadas à crise do coronavírus em Maringá São elas: comissão para recebimento e validação das doações; comissão de validação de procedimento operacional padrão; comissão de vigilância epidemiológica ativa e comissão de análise das solicitações de atividades essenciais.] [Gabinete Integrado de Acompanhamento à Epidemia do Novo Coronavírus (Giac-COVID-19) no Estado do Paraná. Além do Ministério Público do Paraná, compõem o gabinete integrado o Ministério Público Federal, o Ministério Público do Trabalho, o Conselho Nacional de Secretarias Municipais de Saúde (Conasems/PR) e o Conselho Nacional de Secretários Estaduais de Saúde (Conass/PR). macrorregiões (Curitiba, Cascavel, Londrina e Maringá).]

\section{Mauá-SP}

[Batizado como Cecco (Centro Especializado de Combate ao Coronavírus).]

\section{Natal-RN}

[Fica instituído o Gabinete de Crise COVID-19, com a função de coordenar as ações do Governo Municipal no enfrentamento e prevenção de disseminação da COVID-19, composto pelo:

I - Prefeito Municipal, que o presidirá;

\| - Secretário Municipal de Governo;

III - Secretário Municipal de Comunicação Social;

IV - Secretário Municipal Saúde;

V - Secretário Municipal de Educação;

VI - Secretário Municipal de Segurança Pública e Defesa Social;

VII - Secretário Municipal de Trabalho e Assistência Social;

VIII - Secretário Municipal de Administração.] 


\section{Descrição das colaborações dentro do setor público}

\section{Niterói-RJ}

[Cria Gabinete de Crise para centralizar a tomada de decisões, integrar e alinhar as iniciativas do Município na prevenção e assistência à população em relação à disseminação do vírus COVID-19 no Município de Niterói e dá outras providências.]

\section{Nova Lima-MG}

[Centro de Operações em emergência em saúde][A Prefeitura Municipal de Nova Lima, por meio do comitê de combate ao novo coronavírus][Instituído o Gabinete de Crise que será responsável pelo monitoramento e tomada de decisões, visando o enfrentamento e combate à pandemia do Novo Coronavírus.]

\section{Patrocínio-MG}

[Comitê Municipal de Enfrentamento do Coronavírus. Ministério Público, Poder Judiciário, Polícia Militar, Polícia Civil, Santa Casa de Patrocínio, ACIP/CDL, SindComércio, Secretaria Municipal de Saúde, Procuradoria Municipal.]

\section{Pinhais-PR}

[Institui o Comitê Municipal Especial de Controle de Infecção da COVID-19 (COMECI - COVID), com o objetivo de propor as estratégias e procedimentos técnicos na esfera da saúde municipal para o enfrentamento da situação epidemiológica atual e dá outras providências.][Fica estabelecido o Programa de Benefício Financeiro Social Temporário aos associados à Associação de Recicladores de Pinhais - AREPI, afetados pela medida preventiva temporária de suspensão de coleta domiciliar de resíduos recicláveis, em razão da situação de emergência oriunda da Pandemia do Coronavírus (COVID-19).]

\section{Porto Alegre-RS}

[Fica instituído o Comitê Temporário de Enfrentamento ao Coronavírus (CTECOV) do Município de Porto Alegre, como mecanismo municipal da gestão coordenada em resposta à emergência na saúde pública.]

\section{Porto Seguro-BA}

[Coordernadora do Comitê Gestor Municipal de Controle do Coronavírus em Feira de Santana.]

\section{Prado-BA}

Não encontrado.

\section{Rancho Queimado-SC}

Não encontrado.

\section{Recife-PE}

[Comitê municipal de resposta rápida em combate a prevenção do novo coronavírus.]

\section{Rio Branco-AC}

[Comitê de Enfrentamento e Monitoramento de Emergência para Infecção Humana pelo Novo Coronavírus (COVID-19) - CEME-COVID-19][Grupo para prevenção ao coronavírus. 0 grupo de trabalho é formado por representantes da Universidade Federal do Acre (UFAC), Colegiado de Diretores de Escolas Públicas, Coordenadoria Municipal de Defesa Civil, SEME e Secretaria Municipal de Saúde (SEMSA).]

\section{Rio de Janeiro-RJ}

[Gabinete de Crise. 0 gabinete, a ser chefiado pelo secretário municipal de Ordem Pública, Gutemberg de Paula Faria, ou por alguém designado por ele, ficará responsável por integrar todos os órgãos da prefeitura em torno das ações contra a doença.] 


\section{Descrição das colaborações dentro do setor público}

\section{Rio Verde-GO}

[Centro de Operações de Emergência em Saúde (COE-COVID-19), coordenado pela Secretaria de Saúde.]

\section{Salvador-BA}

[0 Centro de Operações de Emergências em Saúde Pública (COE-COVID-19) atuará como mecanismo de gestão coordenada da resposta ao enfrentamento do Novo coronavírus no âmbito municipal, ficando sob responsabilidade da Secretaria Municipal da Saúde - SMS a gestão do COE-COVID-19.][A Secretaria Municipal de Desenvolvimento e Urbanismo (Sedur), com o apoio da Guarda Civil Municipal (GCM) e da Polícia Militar (PM-BA), realizou 1.051 vistorias e 91 interdições em estabelecimentos comerciais de Salvador no último fim de semana. Ao todo, cinco alvarás de funcionamento foram cassados. As ações ocorrem para fiscalizar o cumprimento das medidas.]

\section{Santana de Parnaíba-SP}

Não encontrado.

\section{Santo André-SP}

[A Prefeitura de Santo André criou nesta quinta-feira (12) o Comitê Gestor de Contingência do Coronavírus, com 0 objetivo de monitorar o avanço da COVID-19 no município. Fazem parte do comitê representantes da Secretaria de Saúde, Secretaria de Educação, Secretaria de Cidadania e Assistência Social, Secretaria de Desenvolvimento e Geração de Emprego, além da rede de hospitais privados e comunidade acadêmica da Faculdade de Medicina do ABC e Universidade Federal do ABC.]

\section{São Bernardo do Campo-SP}

[A Prefeitura de São Bernardo se antecipou aos fatos e criou, a partir desta sexta-feira (31/01), o "Comitê de Combate ao Coronavírus", que terá a participação de uma equipe multidisciplinar da Saúde e das demais secretarias para, a partir da orientação da secretaria de Saúde do Estado e do Ministério da Saúde, traçar as diretrizes necessárias de prevenção e combate doença na cidade.]

\section{São Caetano do Sul-SP}

[Um dos pedidos do prefeito José Auricchio Júnior, durante as reuniões do Comitê de Emergência e Combate ao Coronavírus, é que tenhamos todas as ferramentas possíveis e disponíveis para essa guerra contra a COVID-19.]

\section{São Paulo-SP}

[Oficializa a Câmara de Integração Institucional, que objetiva integrar os representantes dos Poderes Constituídos e minimizar os impactos decorrentes da situação de emergência e do estado de calamidade pública resultantes da pandemia da COVID-19.]

\section{Sete Lagoas-MG}

[Gabinete Gestor da Crise do Coronavírus (COVID-19) no Município de Sete Lagoas, em razão do estado de emergência em saúde pública ] [ica instalado o Centro de Operações de Emergência em Saúde - COE-SETELAGOAS-COVID-19, coordenado pela Secretaria Municipal de Saúde, para monitoramento da emergência em saúde pública declarada.][Foi iniciada neste domingo, 15, a atuação de um Comitê de Operações Especiais da Saúde em parceria com várias secretarias municipais com o objetivo de determinar ações emergenciais para evitar a propagação do novo Coronavírus em Sete Lagoas.]

\section{Uberlândia-MG}

[Fica instituído o Comitê Municipal de Enfrentamento a COVID-19 com a finalidade implementar ações de caráter preventivo na saúde pública no Município de Uberlândia][Força-Tarefa TEMPORÁRIA e integrada para o exercício da fiscalização de estabelecimentos e atividades quanto ao cumprimento de normas e diretrizes estabelecidas para 0 enfrentamento do NOVO CORONAVÍRUS - COVID-19 no âmbito do município de Uberlândia.]

Nota: Estas são transcrições de sites.

Fonte: Elaborado pelos autores. 


\title{
QUADRO A6 PRESENÇA DE COLABORAÇÕES ENTRE SETOR PÚBLICO E SETOR PRIVADO
}

\section{Descrição das colaborações com o setor privado}

\author{
Anápolis-G0 \\ Não encontrado. \\ Aquiraz-CE \\ Não encontrado.

\section{Barra Mansa-RJ} \\ [A parceria instituída entre a Prefeitura de Barra Mansa, a empresa Saint Gobain e o Restaurante Itinerante começou a \\ possibilitar a partir desta sexta-feira, dia 17, a distribuição de marmitex a moradores de áreas carentes do município. A \\ intenção é entregar a alimentação diariamente, inclusive aos sábados, domingos e feriados.]

\section{Belo Horizonte-MG} \\ Não encontrado.

\section{Belo Jardim-PE} \\ [As empresas Construtora Viana\&Moura, Grupo Cornélio Brennand, Grupo Moura e Ferreira Costa entram com doação. \\ A ONG Novo Jeito e Transforma Brasil coordena as atividades. Tem apoio de prefeituras, governo do Estado e Exército. \\ 0 site é empresariosporpe.com.br.][0 Instituto Conceição Moura doou cestas básicas para escolas e creches da Rede \\ Municipal de Ensino e contou com o apoio da Transportadora Bitury. A alegria chega para as famílias das Creches da \\ Rede Municipal Mocinha Moura, Samaritana, Vovó Maria, os Centros Infantis Jurandir de Brito, Lucielma e Debora \\ Valença ao todo foram distribuídas 1000 cestas.]
}

\section{Braço do Norte-SC}

Não encontrado.

\section{Campo Bom-RS}

[Dezesseis empresas privadas, duas entidades de classe, o principal sindicato de Campo Bom, Legislativo e Executivo Municipal. Todos reunidos em uma teleconferência realizada na tarde de hoje, 31 e que resultou numa iniciativa inédita: a implantação de um comitê público-privado que debaterá ações efetivas e preventivas focadas no desenvolvimento da cidade durante e após a COVID-19.][A comunidade de Campo Bom segue contribuindo e mobilizada para ajudar a combater o coronavírus no município. A Prefeitura de Campo Bom recebeu ao longo da semana doações de empresas, entidades e voluntários que estão sensibilizados com o cenário atual de pandemia e não medem esforços para ajudar ao próximo. Sob o guarda-chuva da frente Todos por Campo Bom - na qual empresas, entidades e sindicato somam esforços pela manutenção do emprego e no combate à fome na cidade - os itens doados essa semana fizeram a diferença na comunidade.]

\section{Campo Grande-MS}

Não encontrado.

\section{Campo Largo-PR}

Não encontrado.

\section{Carapicuíba-SP}

Não encontrado. 


\section{Caxias do Sul-RS}

Não encontrado.

\section{Cianorte-PR}

Não encontrado.

\section{Coronel Fabriciano-MG}

Não encontrado.

\section{Curitiba-PR}

[Curitiba integra a força-tarefa do C40, rede mundial de cidades que busca soluções para problemas decorrentes das mudanças climáticas, para reduzir os impactos econômicos no mundo decorrentes da pandemia do novo coronavírus.] [DOCTORALIA BRASIL SERVIÇOS ONLINE E SOFTWARE LTDA.Doação de uma Plataforma de Streaming, que se caracteriza por uma forma de distribuição I(imagem por vídeo) para melhoria de tempo de resposta do atendimento aos usuários do SUS para contribuir para o combate do Coronavírus (COVID-19) no Município de Curitiba.][BOTICA COMERCIAL FARMACÊUTICA LTDA. Doação de 05 (cinco) mil unidades de gel antisséptico nuvem, cujo produto é destinado a contribuir no combate ao enfrentamento da emergência de saúde pública de importância internacional decorrente do Coronavírus (COVID-19) no Município de Curitiba.]

\section{Divinópolis-MG}

Não encontrado.

\section{Feira de Santana-BA}

Não encontrado.

\section{Ferraz de Vasconcelos-SP}

Não encontrado.

\section{Florianópolis-SC}

[Em parceria com a ACM (Associação Catarinense de Medicina) e a Acate (Associação Catarinense de Tecnologia), o município elabora um plano diretor das tecnologias de informação para o enfrentamento à pandemia. 0 município já começou a enviar SMS para pessoas que morem a até 200m de alguém confirmado com coronavírus.]][A medida é possível graças a parceria com a Associação Catarinense de Tecnologia, que cruza seu banco de dados com os da prefeitura da capital para identificar os destinatários. Iniciado no dia 31 de março, o projeto já havia enviado 98.207 alertas até 0 último domingo.]

\section{Fortaleza-CE}

[Fortaleza está entre as 70 cidades de todos os continentes integrantes de uma força-tarefa internacional para criar estratégias de combate à pandemia do novo coronavírus. 0 projeto Parceria por Cidades Saudáveis (Partnership for Healthy Cities, em inglês), é uma iniciativa financiada pela fundação norte-americana Bloomberg Philanthropies com apoio da Organização Mundial da Saúde (OMS) e da Vital Strategies.][0 objetivo da parceria púbico-privada entre o Sistema Verdes Mares e a Prefeitura de Fortaleza busca ajudar a coletar alimentos, itens de limpeza e doações em dinheiro para auxiliar pessoas que estão impossibilitadas de prestar serviços.][A Prefeitura de Fortaleza lançou nessa sexta-feira, 3, o programa "Todos com Máscara", que tem o objetivo de produzir 2,5 milhões de máscaras de tecido reutilizáveis para distribuir entre a população. 0 projeto será feito em parceria com microempresas e pequenas costureiras que deverão se inscrever para participar através do edital que será lançado até 0 dia 15 de abril. Serão 300 vagas individuais e 24 para pequenas empresas.] 
Descrição das colaborações com 0 setor privado

\section{Foz do Iguaçu-PR}

[Segundo o coordenador, a compra dos 28 mil exames foi feita em duas etapas. Na primeira, a prefeitura e a Unila investiram, ao todo, quase R\$ 260 mil com 8 mil testes da COVID-19. Na segunda etapa, conforme a prefeitura, a Fundação Municipal de Saúde comprou 20 mil testes, com o investimento de $\mathrm{R} \$ 640$ mil. 0 custo médio de cada teste é de $\mathrm{R} \$ 32$. De acordo com a Itaipu Binacional, a usina estuda a criação de um convênio com o município para a contratação de até 1,5 mil leitos de hotéis de Foz do Iguaçu. Os espaços seriam usados para o isolamento dos pacientes infectados.][A partir desta quarta-feira (18), já está em vigência o convênio, no valor de US\$ 3 milhões, firmado entre a usina de Itaipu e a Fundação de Saúde Itaiguapy, responsável pela gestão do Hospital Ministro Costa Cavalcanti (HMCC), para o enfrentamento de um possível surto do coronavírus (COVID-19).][A Prefeitura Municipal de Foz do lguaçu recebeu, na tarde de ontem (13), a doação de 75 litros de álcool glicerinado 80\% da Universidade Federal da Integração Latino-Americana (UNILA). 0 produto, fabricado por pesquisadores da instituição, será utilizado pela Secretaria Municipal de Saúde.][A Fundação Municipal de Saúde, gestora do Hospital Municipal Padre Germano Lauck (HMPGL), já abriu 0 credenciamento para contratação de até 1.500 leitos na rede hoteleira.]

\section{Goiânia-G0}

Não encontrado.

\section{Guarulhos-SP}

Não encontrado.

\section{Ipatinga-MG}

Não encontrado.

\section{Jaboatão dos Guararapes-PE}

Não encontrado.

\section{Joinville-SC}

Não encontrado.

\section{Juiz de Fora-MG}

Não encontrado.

\section{Londrina-PR}

[Coesp (Centro de Operações de Emergências em Saúde Pública) para discutir a retomada progressiva do setor produtivo. A decisão saiu por volta das $21 \mathrm{~h} 30$ de quinta-feira (9). Participam do encontro, além de representantes da prefeitura, a promotora de justiça Suzana Lacerda, de Defesa da Saúde Pública, membros da Acil (Associação Comercial e Industrial de Londrina), da ACP (Associação Comercial do Paraná) e o grupo técnico que compõem o Coesp, profissionais e lideranças médicas da saúde pública e privada. Esse comitê é responsável por gerir ações e tomadas de decisões referentes ao coronavírus em Londrina.]

\section{Maceió-AL}

Não encontrado.

\section{Manaus-AM}

[0 hospital de campanha foi montado pela prefeitura de Manaus. A rede particular de hospitais Samel cedeu pessoal, equipamentos e vai ajudar na gestão.]

\section{Maringá-PR}

Não encontrado. 
Descrição das colaborações com o setor privado

\section{Mauá-SP}

[Frente ao avanço do novo coronavírus (COVID-19) no Brasil, o prefeito de Mauá, Atila Jacomussi, assinou nesta última terçafeira (31) um convênio que estabelece uma parceria público-privada com o Hospital Vital e a Medical Health, o primeiro acordo nesses moldes entre os municípios do ABC. Ao todo, serão até 29 leitos destinados aos pacientes com a patologia, sendo 24 espaços de isolamento e cinco de Unidade de Terapia Intensiva (UTI), equipados com novos respiradores.]

\section{Niterói-RJ}

Não encontrado.

\section{Nova Lima-MG}

Não encontrado.

\section{Patrocínio-MG}

Não encontrado.

\section{Pinhais-PR}

Não encontrado.

\section{Porto Alegre-RS}

Não encontrado.

\section{Porto Seguro-BA}

Não encontrado.

\section{Prado-BA}

Não encontrado.

\section{Rancho Queimado-SC \\ Não encontrado.}

\section{Recife-PE}

[As empresas Construtora Viana\&Moura, Grupo Cornélio Brennand, Grupo Moura e Ferreira Costa entram com doação. A ONG Novo Jeito e Transforma Brasil coordena as atividades. Tem apoio de prefeituras, governo do Estado e Exército. 0 site é empresariosporpe.com.br.]

\section{Rio Branco-AC}

Não encontrado.

\section{Rio de Janeiro-RJ}

Não encontrado.

\section{Rio Verde-GO}

[Centro de Operações de Emergência em Saúde (COE-COVID-19), coordenado pela Secretaria de Saúde. Além de várias agências do governo, envolve empresas, ONGs e entidades religiosas. Ver organograma nas fontes.]

\section{Salvador-BA}

[A campanha Salvador Solidária, criada para ajudar a população no combate aos efeitos da crise provocada pelo novo coronavírus, ganhou reforços de peso: a Câmara de Dirigentes Lojistas (CDL) de Salvador e a Federação das Câmaras de Dirigentes Lojistas do Estado da Bahia (FCDL-BA).Ambas se juntaram à campanha lançada pela Prefeitura de Salvador.] [Um convênio entre a Prefeitura de Salvador e a Fundação Oswaldo Cruz (Fiocruz) ampliou o número de testes para coronavírus que serão realizados na capital baiana.] 


\section{Santana de Parnaíba-SP \\ Não encontrado.}

\section{Santo André-SP}

Não encontrado.

\section{São Bernardo do Campo-SP \\ Não encontrado.}

\section{São Caetano do Sul-SP}

[Como forma de criar alternativas para empreendedores da cidade durante a crise do coronavírus, a Prefeitura de São Caetano do Sul acaba de fechar parceria com a startup Olist. Agora, microempreendedor, pequenas empresas, autônomos, profissionais liberais e artesãos da cidade podem ter sua própria vitrine virtual de forma gratuita no aplicativo. 0 cadastro já está disponível na plataforma on-line Olist Shops ][A iniciativa resulta de parceria com o curso de medicina da Universidade Municipal de São Caetano do Sul (USCS) e o Instituto de Medicina Tropical da Universidade de São Paulo (USP). A General Motors do Brasil emprestou 18 carros para utilização no programa.]

\section{São Paulo-SP}

[Parceria para construção de hospital de campanha.]

\section{Sete Lagoas-MG}

[A cidade de Sete Lagoas terá um hospital de campanha com 20 leitos de média e baixa complexidade. A estrutura será viabilizada por meio de uma parceria entre o Centro Universitário de Sete Lagoas (Unifemm), a organização civil Avante Social e a Prefeitura Municipal.][Unifemm vai realizar a testagem do coronavírus. 0 resultado do exame sairá rapidamente, em torno de 15 minutos. 0 teste detecta o vírus a partir do sétimo dia da infecção; existe essa janela imunológica", explica a reitora.]

\section{Uberlândia-MG}

Não encontrado.

Nota: Estas são transcrições de sites.

Fonte: Elaborado pelos autores.

\section{QUADRO A7 BREVE DESCRIÇÃO DO PROCESSO DE CALIBRAGEM}

\begin{tabular}{|c|c|}
\hline Variável & Procedimento de calibragem (tipo de escala fuzzy) \\
\hline $\begin{array}{l}\text { Munificência de recursos (médicos) } \\
\text { Munificência de recursos (leitos) } \\
\text { Variável resultado }\end{array}$ & $\begin{array}{l}\text { Baseado no quartil, do primeiro ao quarto: } 0 \text { = "totalmente fora", } 0,33=\text { "mais for a } \\
\text { do que dentro", } 0,67=\text { "mais dentro do que fora", and } 1 \text { = "totalmente dentro" }\end{array}$ \\
\hline Vulnerabilidade social & $\begin{array}{l}\text { Baseado nos quartis para o todos os municípios brasileiros, do primeiro ao quarto: } \\
0=\text { "totalmente fora", } 0,33=\text { "mais for a do que dentro", } 0,67=\text { "mais dentro do } \\
\text { que fora", and } 1=\text { "totalmente dentro" }\end{array}$ \\
\hline Programas de auxílio & $\begin{array}{l}0 \text { = nenhum programa de ajuda disponível; } 0,33=\text { um programa de ajuda } \\
\text { disponível; } .67 \text { = programa de dois auxílios disponível; } 1 \text { = programa de três auxílios } \\
\text { disponível }\end{array}$ \\
\hline $\begin{array}{l}\text { Colaboração dentro setor público } \\
\text { Colaboração com o setor privado }\end{array}$ & $\begin{array}{l}0=\text { "totalmente dentro" para a presença deste tipo de colaboração e } 1 \text { = } \\
\text { "totalmente fora" para a ausência }\end{array}$ \\
\hline
\end{tabular}

Nota: O procedimento de calibração, que é o processo de mover de uma matriz de dados brutos para uma matriz recodificada. O método de recodificação consistiu na aplicação de uma escala difusa.

Fonte: Elaborado pelos autores. 
TABELA A8 ESTATÍSTICAS DESCRITIVAS DOS FATORES CONTEXTUAIS

\begin{tabular}{|lrr|rrrr}
\multicolumn{1}{c}{ Variáveis } & Média & $\begin{array}{r}\text { Desvio } \\
\text { padrão }\end{array}$ & Variância & Mínimo & Máximo & $\mathbf{n}$ \\
\hline Leitos por 100 mil habitantes & 2,55 & 6,91 & 47,76 & 0 & 49,24 & 52 \\
Médicos por 100 mil habitantes & 273,29 & 146,17 & $21.365,34$ & 34,75 & 665,94 & 52 \\
Índice de vulnerabilidade social & 0,27 & 0,08 & 0,01 & 0,13 & 0,46 & 52 \\
\hline
\end{tabular}

Fonte: Elaborada pelos autores.

\section{QUADRO A9 COMPARAÇÃO ENTRE AS SOLUÇÕES ENTRE 0 NÚMERO DE DIAS ENTRE 0 PRIMEIRO CASO} E LEGISLAÇÃO FECHANDO LOJAS E ESCOLAS

\begin{tabular}{lll}
$\begin{array}{l}\text { Soluções } \\
\text { 1a }\end{array}$ & $\begin{array}{c}\text { Número de dias entre primeiro caso e } \\
\text { lojas fechadas }\end{array}$ & $\begin{array}{r}\text { Número de dias entre primeiro caso e } \\
\text { escolas fechadas }\end{array}$ \\
\hline 1b & de 3 a 9 (média 7,0$)$ & de 0 a 5 (média 4,5) \\
2 & de 4 a 8 (média 6,0) & de 6 a 13 (média 9,5) \\
Amostra completa & de 4 a 7 (média 7,7$)$ & de 3 a 10 (média 5,7)
\end{tabular}

Fonte: Elaborado pelos autores.

QUADRO A10 SOLUÇÕES VERSUS DATA DO PRIMEIRO CASO

\begin{tabular}{|c|c|c|}
\hline Solução & Município & $\begin{array}{l}\text { Data do primeiro cado se } \\
\text { COVID-19 confirmado }\end{array}$ \\
\hline $1 \mathrm{a}$ & Belo Jardim-PE & 17-Mar-2020 \\
\hline $1 \mathrm{a}$ & Curitiba-PR & 12-Mar-2020 \\
\hline $1 \mathrm{a}$ & Mauá-SP & 16-Mar-2020 \\
\hline $1 \mathrm{a}$ & Rio Verde-GO & 12-Mar-2020 \\
\hline $1 b$ & Pinhais-PR & 17-Mar-2020 \\
\hline $1 b$ & Campo Bom-RS & 10-Mar-2020 \\
\hline 2 & Belo Horizonte-MG & 16-Mar-2020 \\
\hline 2 & Divinópolis-MG & 8-Mar-2020 \\
\hline 2 & Goiânia-G0 & 12-Mar-2020 \\
\hline
\end{tabular}

Fonte: Elaborado pelos autores. 
TABELA A11 SOLUÇÕES VERSUS TAMANHO DA CIDADE

\begin{tabular}{c|cc} 
Solução & Município & $\begin{array}{c}\text { População estimada } \\
\text { em 2019 }\end{array}$ \\
\hline 1a & Belo Jardim-PE & 76.439 \\
\hline 1a & Curitiba-PR & 1.933 .105 \\
\hline 1a & Mauá-SP & 472.912 \\
\hline 1a & Rio Verde-G0 & 235.647 \\
\hline $1 b$ & Pinhais-PR & 132.157 \\
\hline $1 b$ & Campo Bom-RS & 66.712 \\
\hline 2 & Belo Horizonte-MG & 2.512 .070 \\
\hline 2 & Divinópolis-MG & 238.230 \\
\hline 2 & Goiânia-G0 & 1.516 .113 \\
\hline
\end{tabular}

Fonte: Elaborada pelos autores.

FIGURA A12 SOLUÇÕES VERSUS NÚMERO DE CASOS CONFIRMADOS POR 100 MIL HABITANTES

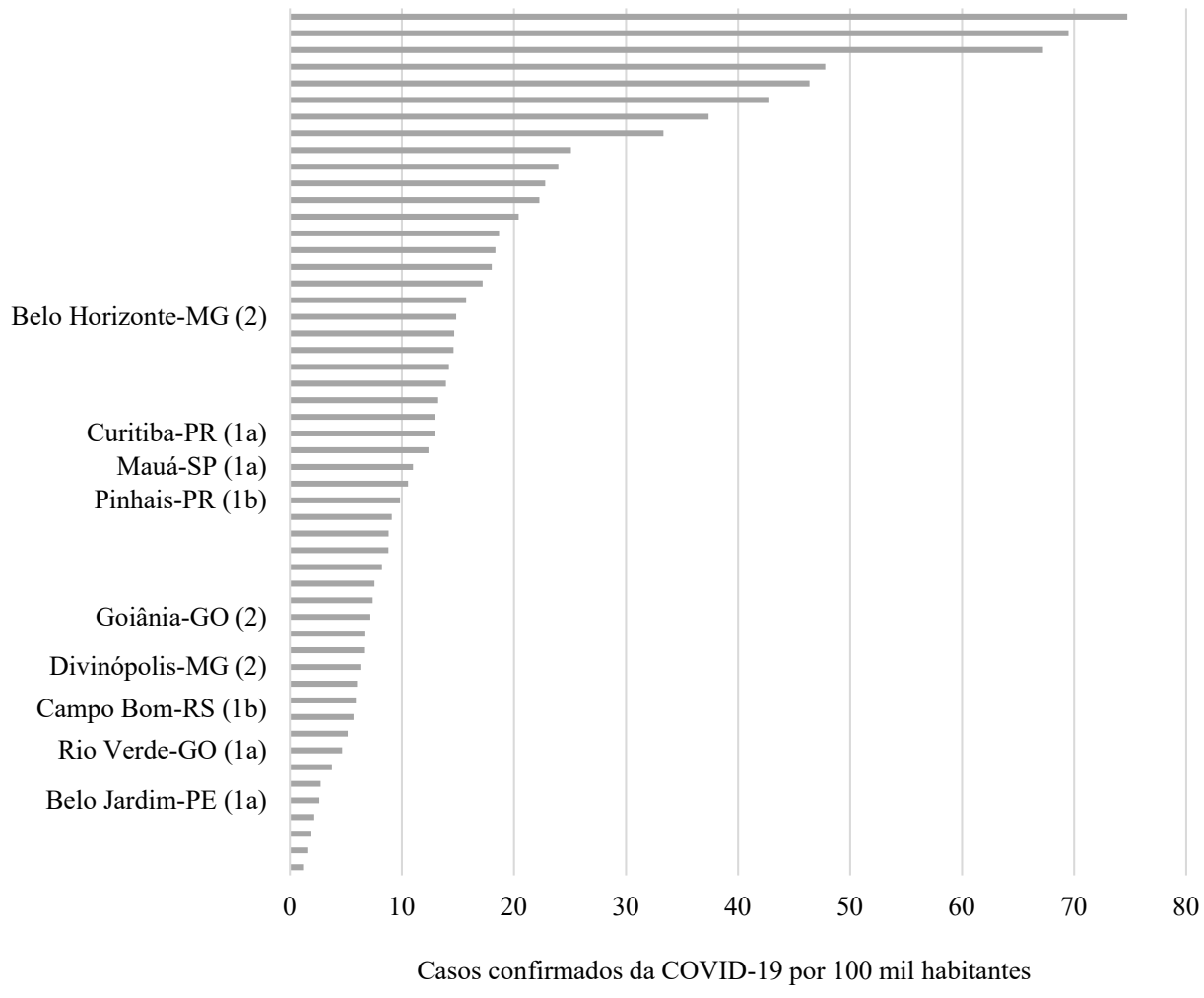

Nota: soluções entre parênteses.

Fonte: Elaborada pelos autores. 
FIGURA A13 TESTE DE ROBUSTEZ COMPARANDO OS RESULTADOS DAS CIDADES DENTRO DAS

SOLUÇÕES E AS CIDADES FORA DA SOLUÇÃO. É POSSÍVEL OBSERVAR UMA PROPAGAÇÃO A UMA TAXA MAIOR NAS CIDADES FORA DA SOLUÇÃO

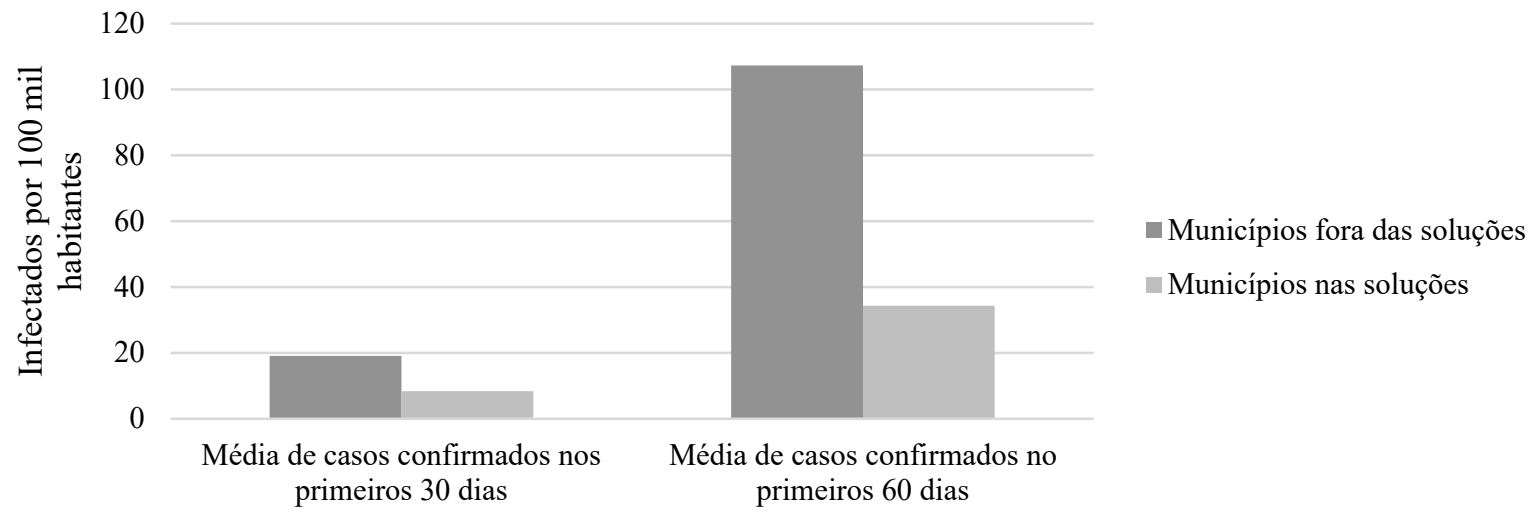

Fonte: Elaborada pelos autores. 